\title{
Exercise for Osteoporosis Prevention: A Health Belief Model Guided Intervention
}

\author{
Hilda Amalia Taylor \\ Massanutten, Virginia \\ BSN, Ball State University, 1978 \\ MSN, University of Virginia, 1987 \\ A Capstone presented to the Graduate Faculty \\ Of the University of Virginia in Candidacy for the Degree of \\ Doctor of Nursing Practice
}

School of Nursing

University of Virginia

December, 2015

Dorothy Tullmann, PhD, RN, CNL

Ishan C. Williams, $\mathrm{PhD}$

Jeanmarie Bechtle, DNP, ANP-BC, CCD 


\section{Table of Contents}

$\begin{array}{ll}\text { Title Page } & 1\end{array}$

Table of Contents 2

$\begin{array}{ll}\text { Abstract } & 5\end{array}$

$\begin{array}{lr}\text { Section I } & 6\end{array}$

$\begin{array}{ll}\text { Introduction } & 6\end{array}$

$\begin{array}{ll}\text { Background and Significance } & 7\end{array}$

$\begin{array}{lr}\text { Exercise } & 9\end{array}$

$\begin{array}{ll}\text { Theoretical Framework } & 10\end{array}$

$\begin{array}{ll}\text { Purpose of Study } & 13\end{array}$

$\begin{array}{ll}\text { Research Question } & 13\end{array}$

Hypothesis $\quad 14$

$\begin{array}{ll}\text { Section II } & 15\end{array}$

Review of the Literature 15

$\begin{array}{ll}\text { Discussion } & 19\end{array}$

Implications for Nurse Health Promotion 21

$\begin{array}{ll}\text { Implications for Capstone Project } & 22\end{array}$

$\begin{array}{ll}\text { Section III } & 24\end{array}$

$\begin{array}{ll}\text { Method } & 24\end{array}$

$\begin{array}{ll}\text { Research Design } & 24\end{array}$

$\begin{array}{ll}\text { Description of the Sample } & 24\end{array}$

$\begin{array}{ll}\text { Setting } & 24\end{array}$

$\begin{array}{ll}\text { Program } & 25\end{array}$

$\begin{array}{ll}\text { Procedures } & 26\end{array}$ 
$\begin{array}{ll}\text { Measures } & 28\end{array}$

$\begin{array}{ll}\text { Data Analysis } & 31\end{array}$

Protection of Human Subjects $\quad 31$

$\begin{array}{ll}\text { Section IV } & 32\end{array}$

$\begin{array}{ll}\text { Results } & 32\end{array}$

$\begin{array}{ll}\text { Discussion } & 38\end{array}$

$\begin{array}{ll}\text { Section V } & 41\end{array}$

$\begin{array}{ll}\text { Manuscripts } & 42\end{array}$

$\begin{array}{ll}\text { References } & 75\end{array}$

$\begin{array}{lrl}\text { Tables } & 81\end{array}$

Table 1 Summary of Demographic and FRAX® Characteristics 81

Table 2 Summation of Revised Osteoporosis Knowledge Test 83

Table 3 Summation of Osteoporosis Health Belief Scale 84

Table 4 Summation of Osteoporosis Self-Efficacy Exercise Scale 85

$\begin{array}{ll}\text { Figures } & 86\end{array}$

Figure 1 Health Belief Model 86

$\begin{array}{ll}\text { Figure } 2 \text { Health Belief Model Variables } & 87\end{array}$

Figure 3 BE fracture FREE Intervention $\quad 88$

Figure 4 Consort Diagram of Study Flow $\quad 89$

Figure 5 Descriptions of Study Variables, Measures and Reliability 90

Figure 6 Permission to use OKT, OHBS and OSES Instruments 92

$\begin{array}{ll}\text { Appendices } & 93\end{array}$

Appendix A Study Participant Recruitment Brochure 93

Appendix B Participant and Principle Investigator Script 94 
Appendix C Consent to Participate 96

Appendix D FRAX® WHO Fracture Risk Assessment Tool 98

Appendix E Demographic Survey 99

Appendix F Osteoporosis Knowledge Test (OKT) Exercise Subscale 100

Appendix G Osteoporosis Health Belief Scale (OSHB) Exercise Subscales 101

Appendix H Osteoporosis Self-Efficacy Scale (OSES) Exercise Subscale 103

Appendix I Sentara RMH Medical Center IRB Approval 104

$\begin{array}{ll}\text { Appendix J Determination of UVA Agent Form } & 106\end{array}$ 


\section{Abstract \\ Exercise for Osteoporosis Prevention: A Health Belief Model Guided Intervention}

Aim: To evaluate the feasibility of conducting a health fair, on bone health, as an intervention to improve the participants' report of their self-efficacy before and after their participation.

Framework: The Health Belief Model (HBM) provides a useful framework to understand health behavior and engage people in preventive activities. Health beliefs influence health behaviors. HBM constructs are valuable guides in designing interventions to promote health behavior modification supporting bone health.

Research question: Will participants in an osteoporosis exercise prevention targeted health fair significantly improve their osteoporosis self-efficacy exercise scores?

Method: Outcome HBM measures used: Revised Osteoporosis Knowledge Exercise Test (OKT), Osteoporosis Health Belief Exercise Scales (OHBS) and Osteoporosis Self-efficacy Exercise Scale (OSES), gaged knowledge, beliefs and self-efficacy for exercise prevention behaviors in a convenience sample population. The exercise promotion health fair intervention was designed to strengthen self-efficacy for osteoporosis exercise prevention behaviors and outcome expectations. The HBM guided health fair was a two hour program lead by an advanced practice nurse who collaborated with community healthcare and fitness professionals. Results: Sixty two participants were screened for their ten year fracture risk probability and assessed to have $\mathrm{a} \geq 10$ score indicating significant risk. They completed pre-program measures and were invited to attend the intervention. Thirty five participants attended BE fracture FREE and completed the post-intervention OSES scale.

Findings: Participant total OSES mean scores for the post- minus pre-program were 26.00 vs 22.46. A paired, two-tailed $t$-test result of $p<0.001,<0.05$ preset alpha, indicated levels of self-efficacy for exercise prevention behaviors significantly improved following the health fair. 


\section{Section I}

\section{Introduction}

To attain high-quality, longer lives free of preventable disease, disability, injury and premature death is a construct in the Healthy People 2020 overarching goals (Center for Disease Control and Prevention, CDC, 2020). Initiatives specify a national health objective to reduce the prevalence of osteoporosis, a disease marked by reduced bone strength leading to an increased risk of fractures. Osteoporosis is best prevented than treated. Fragility fractures result from a fall from a standing height or less, or present in the absence of obvious trauma. They are a serious osteoporosis complication due to underlying fragile bone that significantly decreases the ability to participate in physical activity, or even basic activities of daily living, and negatively impacts general quality of life (National

Osteoporosis Foundation, NOF, 2014). A Healthy People 2020 goal is to prevent illness and disability related to osteoporosis. General lifestyle modification advice that promotes bone health should be offered to all, and most urgently, to those at higher risk for fragility fractures.

Additionally, Healthy People 2020 promotes improving the health, function, and quality of life of older adults (CDC, 2020). Adults over sixty-five years of age are among the fastest growing age groups at higher risk for osteoporosis fracture risks compounded from falls (NOF, 2014). Falls can cause moderate to severe injuries, such as fractures, which significantly increase mortality. Fortunately, falls remain a largely preventable public health problem. A national health objective from Healthy People 2010 is still to increase to $30 \%$ the proportion of adults who perform physical activity that enhances and maintains muscular strength and endurance more than two days per week (CDC, 2011). Older adults stay independent and reduce their chances of falling through regular exercise. The most 
significant exercises focus on increasing leg strength and improving balance, while the exercises become more challenging over time (Christmas \& Anderson, 2000).

Osteoporosis prevention, coupled with reduced fall risk factors aimed at reducing fragility fracture risk, includes early prevention and exercise. Unfortunately, data from the National Health Interview Survey (NHIS) indicates less than twenty percent of older adults engage in enough physical activity, and less than six percent do weight bearing and strength training exercise recommended for bone health (Morbidity \& Mortality Weekly Report, 2004). Christmas and Anderson (2000) encourage health care providers to promote a less sedentary life style for older clients. Aging women,, in particular, with additional fracture risks, such as previous fracture and major fracture parental history, have an even more urgent need for preventive exercise behavior change (NOF, 2014).

\section{Background and Significance}

Osteoporosis is a common and serious bone disorder in aging women characterized by low bone mass and reduced bone strength that is diagnosed by bone mineral density (BMD) levels as defined by the World Health Organization (WHO, 2004). Osteoporosis is a disease in which the net loss of bone surpasses bone formation and is associated with aging. Osteoporosis increases the risk of fractures in older adults that are caused mostly by falling. Typically, osteoporosis goes undiagnosed until a fracture occurs, at which point the disease is already advanced and poses risks of further fractures (Snelling, Crespo, Schaeffer, Smith, \& Walbourn, 2001). As a result early screening and preventive intervention is crucial.

Osteoporosis is a public health issue of growing concern worldwide, with approximately 9 million fractures (Sadat-Ali \& Al-Turki, 2012). Osteoporosis has widespread economic and health impacts. Osteoporosis and osteoporotic fracture complications cause large numbers of disabilities, death, and significant health care costs 
through hospital and rehabilitation expenses (Iannidis, et al., 2009). Although arguably significant strategies including exercise have been proposed in the prevention of osteoporosis, only a few people have engaged in exercise preventive activities. Additionally, risk factors remain, which are beyond change; age, gender, and ethnicity. More women than men are at risk of osteoporosis, with the risk increasing significantly during the postmenopausal period for women, when the majority of fractures are diagnosed (Sadat-Ali \& Al-Turki, 2012). Of the 10 million Americans estimated to have osteoporosis, 8 million are women (NOF, 2014). Caucasian women have a higher incidence of osteoporosis than any other racial or ethnicity group in the United States (U.S.) (Johnson, McLeod, Kennedy, \& McLeod, 2008). Additionally, each fragility fracture event is associated with a significantly increased risk of subsequent fractures compounded by the presence of any additional risk factors (Kemmler, HÃberle \& von Stengel, 2013).

Given the fact that the U.S. population is aging, the U.S is expected to have 14 million osteoporosis cases and more than 47 million Americans with low bone mass, a risk factor of osteoporosis, by 2020 (NOF, 2014). This is an indication that special attention should be given to the prevention of osteoporosis, which starts with identifying for each individual the knowledge and beliefs about osteoporosis and the associated behaviors one has to engage in to reduce their risk of osteoporosis. The NOF 2014 notes the disease remains to be a significant public health threat with approximately 1.5 million fractures each year, and estimates costs to be $\$ 17$ billion annually.

Osteoporosis is a serious threat to the independence, quality of life, and life of postmenopausal women (Estok, Sedlak, Doheny, \& Hall, 2008). Werner (2005), after a comprehensive review of osteoporotic knowledge literature, called on researchers to expand osteoporotic knowledge so as to enhance preventive programs and early diagnosis of 
osteoporosis. Ford and colleagues agreed and noted that the understanding and knowledge that a population has about a disease is a key component of ensuring that effective programs are developed (Ford, Bass \& Zhao, 2011).

\section{Exercise}

Despite the degenerative nature of the disease, several modifiable risk factors are associated with osteoporosis fracture prevention. Most notable factors revolve around supplemented calcium intakes and exercise, advantageous in promoting BMD, coupled with muscle strength and balance training (Snelling et al., 2001). Lee, Jong-Duek, Yang and Yoon (2012) note regular exercisers have stronger femurs than non-exercisers. Strength and aerobic exercises improve stability, balance, and coordination as well as reduce the risk of falls. According to recent NOF and American College of Sports Medicine (ACSM) recommendations to clinicians regarding osteoporosis prevention and treatment, regular exercise, including aerobic and muscle-strengthening, is an essential primary strategy for all adults to control low BMD (ACSM, 2009). Exercise combined with other therapy may result in better treatment outcomes in the higher fracture risk target group of aging postmenopausal women.

Even though a high prevalence of osteoporosis exists in aging populations, Lee et al. (2012) identified their awareness and proven treatment and prevention exercise interventions were low. Their (2012) findings indicate that adults age fifty years or higher are not active enough to acquire the health benefits of practicing recommended amounts of exercise. Due to the benefit associated with exercise, health care providers should instigate sustainable patient prevention programs highlighting the importance of regular exercise including strength training for bone health. Practice should focus on improving adherence to exercise, especially among adults at higher risk for osteoporotic fractures, notably aging 
postmenopausal women; and secondly, on how best to provide appropriate exercise guidance and support to reduce risk for additional osteoporotic fractures.

Estok et al., (2008) note health beliefs drive health behaviors and seek to understand ways to motivate women to initiate and continue health promotion exercise designed to maintain or increase bone density and reduce fall risk. Recommendations and frameworks addressing exercise for osteoporosis prevention can be used to help us understand how best to convey guidance and information in order to engage with people who are experiencing, or are at risk of, osteoporosis difficulties. Furthermore, prevention and guidance can potentially create sustainable behavioral change at a person-centered level. Treatment, however, can be difficult when individuals demonstrate ambivalence towards making changes within their lives that may alter the burden of their condition.

\section{Theoretical Framework}

The Health Belief Model (HBM) is a conceptual framework that conceptualizes health behavior and possible reasons for behavioral choices with recommended health action (Turner, Hunt, DiBrezzo, \& Jones, 2004). The HBM is an individual level theory and explains the reason and under what conditions individuals take preventive actions (Estok et al., 2008).

The HBM is the most-used theory in health education programs and promotion of healthy living (Nguyen, 2014). The original HBM posits that health behavior is determined by individual beliefs or perceptions about a disease and the strategies available to decrease its occurrence (Stretcher \& Rosenstock, 1997). The diagrammatic representation of the revised HBM model is provided in Figure 1.

In light of this original underlying assumption, the HBM helps in determining whether individuals are susceptible to a disease, and if so, theorizes whether the benefits 
they attach to the prevention of the disease are influential to their readiness to act. The HBM has seven constructs used individually or together to explain health behavior.

\section{Perceived seriousness}

Stretcher and Rosenstock (1997) define this construct as one that addresses an individual's belief concerning the seriousness and severity of an illness. The perception of seriousness has its basis in the medical information provided.

\section{Perceived susceptibility}

Stretcher and Rosenstock (1997) describe a person's moves to adopt preventive behaviors are heavily influenced by the person's perceived risk of getting the illness. People who feel they are at higher risk of developing a disease may be more motivated to engage in preventive behaviors that are aimed at decreasing the perceived risk or susceptibility.

\section{Perceived benefits}

Stetcher and Rosenstock (1997) recognize this construct refers to an individual's idea of the usefulness or value of a new behavior intended to reduce their risk of illness. Individuals tend to adopt new behaviors if they perceive the new behaviors as being capable of reducing their risk of disease. Perceived benefits help in influencing an individual to engage in secondary prevention such as exercise behaviors for bone health.

\section{Perceived barriers}

Stretcher and Rosenstock (1997) describe people will basically experience difficulties adopting new behavior changes. As such, perceived barriers refer to individuals' perceptions about the barriers they will face in adopting behavioral changes intended to prevent developing a disease. Perceived barriers are the most significant determinants of behavioral change. For a person to adopt new behaviors, that person must be confident that the new behavior has important benefits that outweigh the results of maintaining the current 
behavior. This way the concerned person will be determined to overcome the perceived barriers and engage in the new healthy or preventive behavior.

\section{Modifying variables}

Stretcher and Rosenstock (1997) recognize modifying variables refer to an individual's personal factors that determine whether the individual will adopt a particular behavior. They are demographic variables such as age and gender, and socio-psychological variables such as personality and social class. Other modifying factors include variables such as culture, level of education, skill, past experiences, motivation, ethnicity and knowledge.

\section{Cues to action}

Stretcher and Rosenstock (1997) identify cues to action have been found to influence behavior. They include events, people, or things that influence people to engage in new habits or behaviors.

\section{Self-efficacy}

This is the self-belief that one possesses an ability needed to accomplish a task (Stretcher \& Rosenstock, 1997). People will most likely make attempts to do things they think they can manage to do. For instance, although a person may be aware that adopting a particular behavior is beneficial to them, they may not try that behavior if they think that they lack the ability to do it.

Nguyen (2014) notes five major HBM constructs associated with the likelihood of engaging in recommended osteoporosis prevention behaviors. They are: perceived susceptibility and perceived severity of osteoporosis, perceived benefits of, perceived barriers to, and self-efficacy for osteoporosis prevention behaviors. The HBM posits that possible barriers to preventive health behaviors, such as non-compliance with recommended 
osteoporosis prevention exercise behaviors, may be impacted by examining HBM constructs (Rosenstock, Strecher \& Becker, 1988). Figure 2 gives a diagram of the HBM with the constructs of interest to the present study.

\section{Purpose of Study}

The proposed study goal was to promote osteoporosis prevention exercise behaviors among populations at higher risk by assessing the knowledge, beliefs, and self-efficacy of risk screened postmenopausal women. Guided by HBM constructs (Rosenstock, Stretcher $\&$ Becker, 1988), the study measured knowledge, beliefs and self-efficacy for exercise prevention behaviors in a sample population. The underlying assumption of the proposed study is that sufficient osteoporosis knowledge mediated by attitudes, beliefs and selfefficacy for bone health exercise preventive behaviors are driving factors in the management of osteoporosis.

\section{Aim 1}

To assess higher risk screened postmenopausal women's baseline knowledge, beliefs and self-efficacy scores of osteoporosis self-managed exercise prevention behaviors.

\section{$\operatorname{Aim} 2$}

To assess and compare pre- and post-intervention Osteoporosis Self-Efficacy Osteoporosis (OSES) scores and analyze differences.

\section{$\operatorname{Aim} 3$}

To explore the effectiveness and feasibility of an osteoporosis exercise prevention health fair targeted for improving self-efficacy and engagement in preventive exercise.

\section{Research question}

Will participants in an osteoporosis exercise prevention targeted health fair significantly improve their OSES score? 


\section{Hypothesis}

Participants who participate in an osteoporosis exercise prevention targeted health fair will have significantly improved OSES scores compared to their baseline scores before the intervention. 


\section{Section II}

\section{Review of the Literature}

A review of the theoretical and empirical literature on osteoporosis knowledge, beliefs, and behaviors and how this literature relates to the HBM is the basis for this literature review. Nguyen (2014) notes the HBM is a useful conceptual framework to understand osteoporosis exercise prevention behaviors and associates the likelihood of engaging in recommended exercise to its constructs.

The review was limited to fifteen osteoporosis or fragility fracture studies published within five years, due to the abundance of relevant trials. The descriptive or interventional studies included were restricted to HBM or Self Efficacy theory guided studies that examined populations of adult women with a mean age greater than 45 years. The focus of the review search was for articles that utilized instruments and study design that noted: osteoporosis knowledge and beliefs including susceptibility, seriousness, benefits, barriers and self-efficacy of exercise and preventive health motivation potential. HBM guided osteoporosis instrument measures, Osteoporosis Knowledge Test (OKT), Osteoporosis Health Belief Scale (OHBS) and Osteoporosis Self-Efficacy Scale (OSES) were key variables in studies incorporated in the review.

\section{Perceived Susceptibility to and Perceived Severity of Osteoporosis}

A common reason for non-compliance to osteoporosis prevention found in the review was the erroneous belief that osteoporosis is not serious (Nguyen, 2014) and few women are taking active measures to prevent osteoporosis even when they believe that it is a serious condition. Most at risk women do not perceive a personal susceptibility to the disease. Only women who reported actively worrying about developing osteoporosis were more likely to be engaged in significant prevention behaviors (Nayak, Roberts, Chung-Chou 
\& Greenspan, 2010). Osteoporosis has frequently been called a "silent disease," due to the fact that it is asymptomatic until a fracture occurs (Werner, 2005).

Giangregorio et al. (2008) found that many individuals who suffer fragility fractures do not associate their fracture with osteoporosis. Inadequate knowledge and/or noncompliance among patients and the lack of a caring, therapeutic partnership with a health provider were two reasons found to be associated with poor exercise participation. Time constraints placed upon primary care providers were a significant barrier to the development of a therapeutic relationship. Communicating a diagnosis of osteoporosis to the patient by a provider was found to be strongly related to a person's perception of future fracture risk. Recommendations from the study included: health care providers should communicate to the patient that advancing age and fragility fracture history increase the risk for future fracture so patients can become active participants in chronic disease management. Ostby et al., (2005) reported osteoporosis chronic disease management time requirements for providing high-quality, comprehensive, guideline-based care exceeds the time allotment to providers for all patient care.

Endicott (2013) reported women with a family history of osteoporosis perceived a greater susceptibility for developing osteoporosis than women without the family history. This study reported significant beliefs in the benefits of exercise in women with an osteoporosis family history. However, his educational intervention in addition to BMD screening and physician referral, while positively influencing osteoporosis knowledge had no effect on exercise prevention behaviors. Tan et al. (2009) identified Chinese women who were concerned about the seriousness of osteoporosis and their relative susceptibility to this disease. In particular, women with a prior fracture reported more concern and took the threats of osteoporosis more seriously. Nonetheless, women exhibited low health 
motivation and low awareness of the benefits of exercise. The women lacked necessary osteoporosis knowledge to develop adequate self-efficacy, which supports the need for effective community osteoporosis prevention behaviors intervention.

\section{Perceived Benefits of and Perceived Barriers to Osteoporosis Exercise Preventive Behaviors}

Estok et al. (2008) reported having a personal knowledge of dual-energy X-ray absorptiometry (DEXA) results that support an osteoporosis diagnosis, significantly increased the postmenopausal women participant calcium intake but not their exercise. In older women, Swaim, Barner and Brown (2008) found that postmenopausal women were neutral on perceived susceptibility to and severity of osteoporosis, but their perceived benefits of exercise were high. However, Tan et al. (2009) found that women over fifty years of age had high perceived susceptibility to and severity of osteoporosis, in particular, women with prior fractures had higher perceived severity to osteoporosis, but had low perceived benefits of weight-bearing exercise. Chang et al. (2010) reported over seventy percent of participants believed they would benefit from osteoporosis exercise prevention behaviors, but sixty-four percent had difficulty in taking action, as only thirty-four percent participated in weight bearing exercise. Participants in the (2014) Ciesielczuk, Glibowski and Szczepanik study recognized exercise was important in preventing osteoporosis and seventy-seven percent undertook some type of exercise prevention behavior. Subjects suffering from osteoporosis had twice as many fractures than healthy subjects. Significant beliefs in the benefits of exercise in women with a family history of osteoporosis were noted in Endicott (2013). Kim et al. (2013) utilized the OHBS to evaluate women with BMD screening and noted younger participants had significant higher benefit of exercise results while older women had lower barriers to exercise. This variance supports tailoring 
interventions to specific age target groups. Plawecki and Chapman (2013) concluded that intention to exercise was modified by peer and family support, thereby, suggesting community-based programs can translate and use clinical trial key topics and outcomes to tailor better osteoporosis exercise prevention behaviors intervention strategies.

\section{Self-efficacy of Osteoporosis Preventive Behavior}

Based on the HBM, people are more likely to engage in osteoporosis prevention behaviors if they believe they can modify their risks. Overall, self-efficacy of exercise correlates positively with exercise participation. Women lacking confidence to perform exercise prevention behaviors, indeed, will have decreased levels of initiating and maintaining effective exercise. Babatunde et al. (2011) support a HBM theory driven approach to improve osteoporosis exercise prevention behaviors in target populations. They reported an educational program was associated with improvement in knowledge, and selfefficacy, but they also acknowledged less effect on health belief subscales including exercise. Endicott (2013) found no difference between pre- and post- test groups in selfefficacy exercise scores. Estok et al. (2008) recommended changes in osteoporosis exercise prevention behavior require more personal involvement and more intensive interventions.

One statistically significant result found in this review was reported in the Qi, Resnick, Smeltzer and Bausell (2011) study. This study stated increased self-efficacy and exercise participation followed an effective educational intervention. Self-efficacy based interventions improve knowledge and the adoption of preventive behaviors associated with bone health. The Qi et al. (2011) study applied the Self-Efficacy Theory to guide their intervention to impact individual capability to perform a course of action to attain a desired outcome. One strategy included setting small individual exercise goals that supported success. Individualized goals and guidance were based on specific screening results, 
previous exercise and behaviors, and different preferences. Additional verbal persuasion tactics, including role models and significant others were emphasized, making the overall activities in a social setting of their peers. Swaim et al., (2008) also concluded self-efficacy was significantly and positively associated with postmenopausal women's performance of osteoporosis exercise prevention behaviors. Improving confidence and engaging in appropriate osteoporosis exercise prevention behaviors, may be beneficial to fracture prevention.

\section{Osteoporosis Knowledge}

Health education and health promotion are proposed effective strategies to improve osteoporosis education, beliefs and thereby exercise preventive behaviors. Osteoporosis prevention education interventions are given with the intention to increase osteoporosis prevention behaviors, such as exercise. However, a review by Werner (2005) found that although these interventions increase osteoporosis knowledge, they do not increase osteoporosis exercise prevention behaviors. Six of the educational intervention studies resulted in increased knowledge outcomes. None of these studies found that increased knowledge led to increased exercise.

\section{Discussion}

The main conclusion from the literature review is that very few studies have been conducted to ascertain how to motivate persons at risk for osteoporosis to engage in exercise to reduce or prevent osteoporosis. Osteoporosis disease prevention and reduction involves engaging target populations in regular exercise that is weight bearing and muscle strengthening in nature (NOF, 2014). However, the percentage of the higher risk target group that engages in preventive exercise is low.

Previous studies suggest that perceived susceptibility to and perceived severity of 
osteoporosis varied and requires individualized osteoporosis knowledge, beliefs and selfefficacy assessment prior to creating and implementing an intervention to alter osteoporosis exercise prevention behaviors. Perceived benefits of and barriers to, plus self-efficacy for osteoporosis exercise prevention behaviors, were demonstrated to be modifiable. Knowledge of osteoporosis is only general, which suggests the need of increased promotion and esteem for efficacious osteoporosis exercise prevention behaviors. Therefore, altering osteoporosis knowledge, beliefs and self-efficacy can increase osteoporosis exercise prevention behaviors.

The HBM framework can provide guidelines for program development allowing planners to understand, address and predict reasons for non-compliance. Tailoring interventions to address knowledge, beliefs and self-efficacy perceptions that impact the exercise behaviors of higher risk postmenopausal women's health beliefs is necessary to change behavior. One must consider these issues when planning interventions or promoting health behaviors that may help improve osteoporosis exercise prevention behaviors. In addition, there are modifying factors that can effect behavior compliance. Modifying factors would include media, health professionals, personal relationships, incentives, and selfefficacy of recommended health action. Effective strategies to promote exercise are needed for higher risk women to protect the health of these vulnerable populations most at risk for osteoporosis fractures.

Barriers impede a person's potential to engage in beneficial exercise routines that specifically target osteoporosis prevention and self-management (Qi et al., 2011). The most common barrier is the lack of, which is one's belief in his/her ability to succeed in specific situations. Many thought processes, emotional states, and patterns of behavior determine a person's level of motivation and will power to self-regulate. In this study, self-efficacy 
levels determine whether an at-risk osteoporosis candidate can achieve the will power to engage in osteoporosis preventive behaviors (Qi et al., 2011). In addition to self-efficacy levels influence an individual's ability to prevent disease complications, but knowledge of the disease and a person's core beliefs determine how they view the threat of severity of osteoporosis (Nguyen, 2014). Improving motivation levels and educating people on osteoporosis remains paramount in disease prevention. If a patient's perceptions, beliefs, behaviors and levels of knowledge could be understood, then a health-care provider could discover the triggers that drive self-efficacy to engage in osteoporosis exercise prevention behaviors.

McLeod and Johnson (2011) conclude that theoretically informed interventions are more effective in changing health behaviors in practice than those developed without theoretical basis. By considering the most common osteoporosis exercise prevention health beliefs, such as benefits to, barriers for and self-efficacy, when planning education interventions, we may better address the factors that lead to health behavior change therein, improving prevention and management of osteoporosis.

\section{Implications for Nurse Health Promotion}

In today's society, citizens are encouraged to play an increasingly active role in health decision planning and behavior lifestyle changes that manage various aspects of one's health. Casentini et al. (2011) define having a good "Health Literacy" means to have the skills to take responsibility for personal health, the ability to provide basic self-care, the knowledge of the health care system, understanding the advice and instructions of health professionals, and interactively participating in the process of therapy. Having inadequate levels of these skills, or altogether lacking them, will affect the quality of health in addition to the costs. The nurse plays a vital role in health promotion as an important determinant of 
both health and welfare of the patient.

Regarding various levels of osteoporosis fracture prevention, the nurse assumes a fundamental role for providing patient information, assessment and intervention related to the risks of wrong patient behavior and the benefits to lifestyle behavior modification. The prevention of skeletal fragility and fractures, typical of osteoporosis, can be accessed at three levels: 1) Primary: all measures taken in the general population to be analyzed irrelevant of individual risk; 2) Secondary: early detection of osteoporosis using algorithms to estimate fracture risk; and 3) Tertiary: post osteoporosis fracture and or current symptoms of skeletal frailty (Casentini et al., 2011).

Promoting self-managed osteoporosis exercise modifiers in identified higher risk target groups is essential. Effective tertiary prevention is a key moment to reduce the health and social impact of osteoporosis fragility fractures, because it targets a population with particularly higher risk of fracture (Casentini et al., 2011). An essential prerequisite to any intervention plan is certainly to advise a change in wrong lifestyles, such as sedentary. In particular, personalized exercises aimed at muscle strengthening, rehabilitation of gait, and improving balance in order to reduce (especially high risk assessed aging women) the risk of falls and injuries related to them, must be introduced and managed by the nurse.

\section{Implications for Capstone Project}

Health promotion interventions for higher risk women that combine exercise modalities with education and customized motivation support are limited in the literature. Many exercise trials for women at higher risk for fragility fracture do not incorporate individualized exercise counseling, and many educational intervention trials do not incorporate supervised exercise support. Studies that followed participation in a pilot health promotion program, where subjects had meaningful improvements in self-efficacy, and 
intention to initiate new exercise are lacking.

Pilot studies are an important first step with a new intervention to identify barriers and issues to address before implementing a larger study. The study feasibility, effectiveness and outcome results will increase knowledge of a vulnerable high risk population's exercise barriers. Such knowledge will assist intra-professional practitioners to explore the interactive methods of a HBM guided intervention designed to improve selfefficacy for self-management osteoporosis exercise preventive behaviors. 


\section{Section III}

\section{Method}

\section{Research Design}

This study employed a pre-experimental, one-group pre and post-test design to evaluate the effectiveness and feasibility of a targeted osteoporosis exercise intervention.

\section{Description of the Sample}

The convenience sample was comprised of postmenopausal women independently living in a community hospital service area. Volunteering and consenting women who met study inclusion criteria were screened. Those who scored $\geq 10 \%$ fracture risk on the Fracture Risk Assessment Tool (FRAX®) were invited by the principal investigator to participate in the initial survey measures. A study goal minimum of thirty participants who met intervention inclusion criteria and completed the initial study survey measures were invited to participate in the intervention.

\section{Inclusion criteria:}

1. Postmenopausal women (50+ years of age)

3. English speaking

5. FRAX ${ }^{\circledR}$ screened $\geq 10 \%$ osteoporotic fracture risk score (over four weeks)

6. Complete study baseline survey measures (over four weeks)

\section{Exclusion criteria:}

1. Medical restrictions prohibiting preventive exercise

\section{Setting}

The study was conducted at a community hospital medical center, a 238-bed acute care facility located in northwestern Virginia, which is an affiliate of a nonprofit healthcare organization and serves a seven county area with a population of close to 218,000 . The 
stated mission of the hospital is to "improve the health status of the community by maintaining, enhancing and restoring personal health and well-being." Specialty service divisions relative to the study include an Orthopedic and Sports Medicine Center (diagnostic and treatment), a Women's Center (bone density testing, special events, education and support), and a Wellness Center (medical-based fitness). Additional services include acute inpatient and outpatient rehabilitation including specialty certified therapists in women's health and the Senior Advantage membership program promoting community health.

\section{Program}

The osteoporosis self-management BE fracture FREE exercise promotion health fair intervention outlined in Figure 3 was designed to strengthen self-efficacy for osteoporosis exercise prevention behaviors and outcome expectations. The HBM guided exercise promotion health fair was a two hour program lead by an advanced practice nurse collaborating with community healthcare and fitness professionals. BE fracture FREE was held in a community education convention area located in the health system's women's center.

Registered nurses initially interviewed, measured and weighed participants. Each applicant was FRAX® assessed, given their printed assessment and encouraged to review their results with health care providers.

Educational components included a review of materials from the National Osteoporosis Foundation (NOF) relevant to effective exercise intervention, with emphasis on discussion and application of the information. The seriousness of and susceptibility to developing osteoporosis and recommended health measures was discussed with the audience. The benefits and barriers of exercise was the focus. Participants were encouraged to ask questions and express concerns. Following the initial program, participants viewed 
individual vendor displays that presented exercise modalities available in the community. Experts showcased a variety of exercise prevention methods proven effective for osteoporosis self-management. Additionally, the program included age relevant role models who demonstrated exercise and engaged participants in a variety of bone health methods (i.e. Tai Chi, mountain biking, Golden Zumba, Nia, resistance training, balance and flexibility training, aerobic dance, Pilates, brisk walking, and hiking). Participants were encouraged to share with others their lived experience with exercise success and fracture history. Strategies were directed at changing attitudes, through self-monitoring, presenting exercise as an enjoyable process, setting goals regarding exercise, and increasing knowledge regarding the need and importance of exercise behaviors.

Participants were coached to set small individual goals for exercise that could be mastered so they may experience success. Current physical activity levels were incorporated in individualized goals. Participants were encouraged to make small improvements toward an effective goal of exercise, three times per week, 20-30 minutes of weight bearing and resistive training exercise.

\section{Procedures}

Figure 4 maps the study's participant enrollment, screening, measures, intervention, allocation, follow up and analysis. The principal investigator developed and displayed a recruitment brochure that described the study in service areas of the community hospital health system. Appendix A provides the study participant recruitment brochure. Potential participants voluntarily contacted the principal investigator and provided their FRAX® screening information. The information was communicated via computer qualtrics input, phone or face-to-face interview. Potential participant and principal investigator communication followed a script provided in Appendix B. Over a four week data collection 
time, the principal investigator screened and invited study participants who met qualifying intervention criteria to complete three forms: a written consent, demographic questionnaire and baseline survey measures. Appendix $\mathrm{C}$ provides the written consent. To achieve the initial study aim, the principal investigator assessed participants' baseline knowledge, beliefs and self-efficacy for osteoporosis self-management exercise prevention behaviors using the revised Osteoporosis Knowledge (OKT) exercise subscale, Osteoporosis Health Belief Scale (OHBS) exercise subscale and Osteoporosis Self-Efficacy Scale (OSES) exercise subscale instrument scores. The overall knowledge of risk factors, beliefs about exercise, and barriers to engaging in bone health promotion behaviors was analyzed by the investigator. The results were utilized to tailor an exercise health promotion fair intervention to improve participant exercise self-efficacy.

To achieve the second study aim, the principal investigator assessed and compared pre- and post-intervention participant OSES instrument scores to determine if the intervention significantly improved osteoporosis self-efficacy exercise scores. The intervention participant's self-efficacy for exercise engagement and outcome was assessed. The OSES pre- and post-intervention results were compared.

The final study aim, to investigate the effectiveness and feasibility of a health fair designed for improving self-efficacy for engagement in preventive exercise, was achieved by analyzing the intervention follow-up outcome variables. Over a two-week time, the principal investigator contacted study participants who failed to attend the intervention and identified their reported barriers. Intervention participants were contacted over a two week follow up time to identify their reported change in self-efficacy and current barriers for engaging in osteoporosis exercise prevention behaviors. The investigator determined participant response to identify whether they engaged in exercise activities that may enhance 
bone health and hence reduce osteoporosis complications. Figure 5 provides the study intervention follow-up outcome variables, including barriers to attending the intervention or attendees who initiated new exercise programs, made changes to current exercise behaviors or set goals to make changes.

\section{Measures}

Study instruments were utilized to collect data on the study variables. The questionnaires are standardized, valid and reliable instruments (McLeod \& Johnson, 2011). The measures relate to the HBM constructs and are validated in prior studies (Nguyen, 2014). The following is a description of the instruments summarized in Figure 5. Figure 6 provides the permission authorization for use of the OKT revised (2012), OHBS and OSES instruments.

\section{World Health Organization (WHO) Fracture Risk Assessment Tool (FRAX®):}

The FRAX ${ }^{\circledR}$ Calculator is an online fracture risk assessment measure that can calculate an individual's 10-year risk of fracture (WHO, 2008). The principal investigator assisted the participant in using the FRAX ${ }^{\circledR}$ calculator to generate a numeric value for the likelihood of their developing a major osteoporotic fracture or a hip fracture in the next 10 years. A finding of $\geq 3$ in the hip or $\geq 20$ for major osteoporotic fracture is considered a significant predictor of risk for future fracture (WHO, 2008). FRAX® is easily accessed at the following website: http://shef.ac.uk/FRAX/tool.aspx?country=9. Appendix D provides the FRAX® assessment content.

Demographic Survey: Socio-demographic items include a self-report of descriptive information pertinent to osteoporosis risks. Categories include: initials, two contact numbers or emails, age, gender race/ethnicity, age of menopause, current physical activity and personal health history information. Refer to Appendix E for a listing of all survey 
items.

Osteoporosis Knowledge Test (OKT): The OKT developed by Kim and colleagues (1991) and revised (2012) measures the extent of osteoporosis knowledge a person has. The OKT revised (2012) is a 24-item tool consisting of 9 items measuring overall osteoporosis risk factor knowledge and two subscales, namely OKT Exercise, consisting of 6 items, and OKT Calcium containing 9 items (Gendler et al., 2011). Subjects rated the 6 exercise item subscale that pertained to knowledge of exercise as a preventive behavior for osteoporosis. The items take the form of multiple choice questions with Don't Know responses viewed as incorrect. The total score ranges from 0 to 6 with higher scores indicating the individual is highly knowledgeable about exercise effects on osteoporosis and therefore may engage in preventive exercise behaviors. Refer to Appendix F for a list of survey items and to Figure 5 for reliability results.

Osteoporosis Health Belief Scale (OHBS): Several studies have used the OHBS or subscales to assess osteoporosis beliefs (Nguyen, 2014). The OHBS developed by Kim et al., (1991), is a 42-item instrument, based on the HBM. OHBS examines beliefs related to exercise and calcium intake using seven subscales including susceptibility, seriousness, benefits and barriers of exercise and calcium and health motivation. The modified OHBS scale utilized in this study consists of two OHBS subscales, benefits and barriers to exercise.

The exercise benefits subscale consists of six items that measure the perceived beliefs related to specific exercise behaviors in the prevention of osteoporosis. Questions on exercise address the ability of exercise to prevent osteoporosis, the impact of regular exercise on bone health and the individual's feeling about exercise in the prevention of osteoporosis.

The exercise barriers subscale consists of six items that focus on the difficulties of 
preventive exercise behaviors for osteoporosis. Questions on mental and physical ability to engage in regular exercise, time and facilities for exercise, and family discouragement are used to assess barriers to exercise. Each item is scored on a 5-point scale, with a total score ranging from $1-30$ for each subscale. Refer to Appendix $G$ for a complete list of all survey items and to Figure 5 for reliability results.

Osteoporosis Self-Efficacy Scale (OSES): The OSES is used to measure subject self-efficacy, or the confidence one has in performing the exercise and calcium behaviors specifically related to osteoporosis prevention (Gendler et al., 1991). The OSES is a 12-item instrument consisting of two subscales; namely, osteoporosis self-efficacy exercise consisting of 6 items and osteoporosis self-efficacy calcium consisting of another 6 items. OSES relies on perceived susceptibility and seriousness, perceived barriers and benefits, health motivation, and self-confidence in a person to undertake required osteoporosis preventive behaviors, as a way of predicting health behavior that may possibly occur (Endicott, 2013). The self-efficacy for exercise, measured by the use of six exercise subscale items, measures an individual's confidence at various levels of an exercise program, including the commencement of a new exercise, changing habits of an exercise, applying appropriate effort in the exercise, completion of difficult exercises, time involvement, and the individuals' compliance with the recommended exercise (Swaim et al., 2008). This study omits the calcium subscale as calcium is not the focus of this study. Each item is scored on a 5-point scale that correlates with answers Strongly Disagree, Disagree, Neutral, Agree and Strongly Agree. There is a total score ranging from 6 - 30. Higher scores on the OSES scale imply that the participant believes in one's ability to successfully complete exercise programs. Refer to Appendix $\mathrm{H}$ for a complete list of all survey items and to Figure 5 for reliability results. 


\section{Data Analysis}

After data collection, the researcher entered all data on an Excel spreadsheet using participant number only as the identifier. The data were double entered to assure accuracy and cleaned by checking for outliers. A separate list of participant initials and contact information with participant number for cross-reference was stored in a computer file that is password protected and only accessible by the principal investigator.

Descriptive statistics were computed to describe the sample demographic survey variables and the outcome measures. Quantitative data from the surveys was analyzed using SPSS® Version 22. To address the study hypothesis, perceived exercise self-efficacy is higher in those participants who attended BE fracture FREE than those who did not; a 2tailed Paired $t$ Test was used to detect changes before and after the intervention. A significance level of $p<0.05$ was used for all tests.

\section{Protection of Human Subjects}

This proposal was approved by the Institutional Review Board (IRB) of Sentara RMH Medical Center. The Sentara RMH Medical Center IRB certificate of approval is provided in Appendix I. The University of Virginia (UVA) IRB procedure was also completed. Appendix J provides the UVA IRB Determination Form approval. Participants signed an informed consent provided in Appendix C prior to participating in the study. Upon closure of the study, the surveys, and identification logs will be destroyed via shredding. 


\section{Section IV}

Results

The capstone study was implemented over an eight week timeframe to assess the higher risk FRAX® screened participants' knowledge, beliefs and self-efficacy for osteoporosis self-managed prevention exercise behaviors. Following IRB approval, promotional and recruitment brochures were distributed in the medical center service areas and in local public advertising locations.

The sample population consisted of 111 women who responded and were FRAX® screened. Forty nine were excluded who scored $<10 \%$ risk or declined to participate further. Sixty two consented to participate in the study, all of whom completed the preintervention measures. Additionally, these 62 women were invited and encouraged to attend the BE fracture FREE intervention held June 23, 2015. All potential study participants were invited to the public health promotion intervention regardless of eligibility to participate in the study.

Of the women who attended the health promotion BE fracture FREE program, 35 who represented $56 \%$ of the original sample of 62 completed both the pre- and postintervention measures. Twenty seven who represented $44 \%$ of the sample did not attend, as they had barriers categorized as date and time conflicts, location, and lack of interest or were not able to be contacted. Figure 4 consort diagram of the study flow illustrates the participant outcomes.

Registered nurses verified each participant's FRAX® score by measuring their height and weight. Additionally, they interviewed each participant and reviewed their individual risk factors. Participants received a copy of their individual FRAX® assessment and were advised to share their results with health professionals. Study participants received 
bone health information and encouragement during the program from professional exercise specialists and registered nurses.

Osteoporosis disease information was presented with risk factors and diagnosis criteria emphasized. Only one participant was able to identify their personal Dual-energy Xray Absorptiometry (DEXA) T-score and subsequent osteoporosis diagnosis while several women acknowledged they knew they possessed an osteoporosis diagnosis but were unaware of their T-score. Osteoporosis diagnosis was not an inclusion criteria for participation in this study, as women with high FRAX® risk scores may not be diagnosed or have knowledge of disease presence. All women regardless of an osteoporosis diagnosis were recruited for their bone health intervention potential.

The descriptive analysis of demographic and FRAX® risk characteristics are displayed in Table 1. Non-modifiable fracture risk factors include gender, race/ethnicity and parental fracture history. The majority of aging women meeting inclusion criteria for the convenience sample were Caucasian. Fifty five (89\%) of the women were Caucasian and 7 (11\%) of the women were African American. There were no other racial or ethnic groups represented. Seventeen or $27 \%$ had increased risk due to their parental hip fracture history. Concomitant diagnosis of osteoporosis fracture or rheumatoid arthritis increased fracture risk. The study participants with rheumatoid arthritis totaled 11(18\%), and $23(37 \%)$ were identified with a previous fracture. Behaviors that contributed to the sample's higher screening scores included 17 (27\%) who smoke and 17 (27\%) who consume alcohol daily. Preventive physical exercise decreased risk scores. Fourteen (23\%) total participants reported exercise; but only $9(14 \%)$ participants identified compliance with the recommended frequency of $>3$ times a week.

The two independent groups, the group that attended BE fracture FREE $(n=35)$ and 
the group that did not attend $(n=27)$ were compared using the exact chi-square test for categorical variables and an independent $t$-test for continuous variables. Only the weight was found to be statistically significant $\mathrm{p}<0.05$ preset alpha. The bone health fair participants mean weight was 11.72 pounds lower than the mean weight of the group that did not attend. No distinguishing features between groups were identified to warrant additional intervention target objectives. Additionally, no group differences were noted to contribute to the barriers to attending the intervention.

Table 2 outlines the pre-intervention participants $(\mathrm{N}=62)$ OKT results. The total score mean was 3.31(SD 1.62) and responses ranged 0-6 of a possible 0-6 score. Four was the most frequent score, achieved by 19 individuals, who totaled $31 \%$. The majority of participants chose aerobic dancing as the best for reducing a person's chances of developing osteoporosis. This was the higher percentage correct item answer chosen in the scale. The sample of individuals who answered it correctly totaled 47 which equaled $76 \%$. Question 1, to strengthen bones, it is recommended that a person exercise at a moderately intense level for 30 minutes a day at least 5 days a week was answered correctly by 20 individuals, comprising $32 \%$, and noted as the lower correct item answer chosen in the scale. All other items had a correct score $\geq 50 \%$ with scores ranging from $50 \%-61 \%$. The OKT 3.31 (SD 1.62) mean score indicates median knowledge about exercise effects on osteoporosis and therefore engagement potential in preventive exercise behaviors may improve with additional knowledge interventions.

The group that attended BE fracture FREE and the group that did not attend OKT mean scores were statistically analyzed for differences using an independent $t$-test. Three individual questions plus the total score were statistically significant with $\mathrm{p}<0.05$ preset alpha. The group that did not attend the intervention scored a higher mean on each of three 
individual OKT questions, (\#2) 0.44 higher, (\#4) 0.74 higher and (\#5) 0.77 higher but overall scored 0.87 lower on the total measure mean score. Groups' OKT mean scores, 3.69 (SD 1.28), 2.82 (SD 1.88) and 3.31 (SD 1.62) were middle range of the possible 0-6 score, thereby, leaving room for knowledge growth. The tailored knowledge information presentations and reinforcements pertinent to the participant knowledge deficits were key intervention design components. BE fracture FREE was planned to include both NOF knowledge handouts, on site information, and health and exercise professionals to demonstrate exercise modes and encourage individuals to engage in recommended exercise methods. Refer to Appendix F for a list of OKT questions and Figure 3 for a description of the intervention.

Table 3 outlines the pre-intervention participants $(\mathrm{N}=62)$ OHBS results. Each item is scored on a 5-point scale, with a total score ranging from 1-30 for each subscale. The benefits of exercise total participant mean score was 25.05 (SD 2.71), and ranged 19-30; while the barriers to exercise total participant mean score was 16.45 (SD 4.16) and ranged 624. Pre-intervention individuals $(\mathrm{N}=62)$ completed two subscales designed to measure their perceived beliefs related to specific exercise behaviors in the prevention of osteoporosis. The cumulative results of the benefits of exercise items indicate study individuals agree to strongly agree that they feel positive about exercise and believe that regular exercise benefits osteoporosis prevention. Study results indicate individuals' are cumulatively neutral on items showing they have mental and physical ability to engage in regular exercise, time and facilities for exercise. Results indicate strong disagreement that family discouragement was a barrier to exercise. Benefits scores indicate individuals' value exercise and support an intervention opportunity to improve exercise behaviors while barriers scores are more neutral indicating less potential for obstacles to impede exercise behaviors. 
The group that attended BE fracture FREE and the group that did not attend OHBS mean scores were compared using an independent $t$-test. Comparing the groups for differences on the barriers subscale indicates no significant results. Benefit subscale question \#3 plus the total benefits mean scores indicate statistical significance with $\mathrm{p}<0.05$. The group that attended the intervention scored a 0.33 higher mean on the OHBS benefit question \#3 and overall scored 1.47 higher on the total measure mean result. Groups' OHBS mean scores, 25.69 (SD 2.36), 24.22 (SD 2.94) and 25.05 (SD 2.71) indicate higher ranges of the possible 1-30 score, thereby, supporting study individuals believe there are benefits of achieving the recommended exercise activity. The significant pre-intervention higher score in the group who attended the intervention may indicate a superior believe in the benefits of preventive exercise behaviors that motivated them to attend. Refer to Appendix G for a list of OHBS questions.

In order to assess and compare post- minus pre-intervention osteoporosis selfefficacy scores, intervention attendees completed a post-intervention osteoporosis selfefficacy scale. Table 4 outlines the total pre- $(\mathrm{N}=62)$, post-intervention $(n=35)$ and nonattendance $(\mathrm{n}=27)$ participants' OSES results. Each item was scored on a 5-point scale from 1 ("strongly disagree") to 5 ("strongly agree"). The 6 measured exercise subscale items indicate the individuals' confidence at various levels of an exercise program including the commencement of a new exercise, changing habits of an exercise, and applying appropriate effort in the exercise, completion of difficult exercises, time involvement, and their compliance with recommended exercise. Higher scores imply that the participant believes they have the ability to successfully complete recommended exercise programs. The study total participant pre-intervention results indicate individuals chose agree to strongly agree on all items, with a 20.94 (SD 4.81) mean total score comprising $69 \%$ of the potential score. 
Therefore, the baseline confidence level was positive and provided a promising motivational platform to build on. The measured pair participants' pre-intervention scores were similar to the whole sample with a 22.46 (SD 4.28) mean total score comprising $75 \%$ of the possible score percentile. The post-intervention scores were significantly more positive with a 26.00 (SD 2.81) total mean score comprising $87 \%$ of the feasible score. This 3.54 (SD 2.72) increase in the total mean score for matched pairs $(n=35)$ indicates a $12 \%$ improved osteoporosis self-efficacy for exercise result.

Assumptions for the paired, 2-tailed $t$-test were met with two paired OSES measurements, a continuous level dependent variable and normal distribution results. Postand pre-intervention paired measures were calculated and the self-efficacy score differences between two related observations were compared. IBM® SPSS ${ }^{\circ}$ version 22 computed a 2 tailed significance of $p<0.001,<0.05$ preset alpha; therefore the hypothesis that those participating in an osteoporosis exercise prevention targeted health fair will significantly improve OSES scores compared to their baseline scores is supported. The difference in mean OSES scores between the post-intervention minus the pre-intervention scores is significantly different, therefore the difference in perceived self-efficacy before and after BE fracture FREE is evaluated as significant. The total score mean difference between postand pre-intervention scores was 3.54 (SD 2.72). We are confident that $95 \%$ of the time, the true difference in mean scores will be between 2.17 and 4.34 points.

The group that attended BE fracture FREE and the group that did not attend preOSES mean scores, 22.46 (SD 4.28) and 19.11(SD 5.06) were statistically analyzed for differences using an independent $t$-test. The pre-fair group's comparison indicated significant differences with $\mathrm{p}<0.05$ preset alpha. The group that attended the intervention scored a 3.54 (2.72) higher mean on the pre-OSES total measure result. The group's 
significantly lower mean score who did not attend the intervention may reflect their low motivation to engage in exercise and therefore a related lack of motivation to attend an intervention. All potential study individuals were encouraged to attend the public BE fracture FREE intervention. General public promotion advertisements also notified target population individuals. Refer to Appendix $\mathrm{H}$ for a list of OSES questions.

At two weeks post intervention participants were contacted and they reported their results as: 19 made changes in their exercise behaviors, 5 set new goals for change and 2 initiated new exercise programs while 16 made no changes.

The study showed that this community exercise fair aimed at improving self-efficacy for exercise in higher fracture risk aging women was feasible and effective. One's selfefficacy to exercise could be influenced by a two hour bone health fair that exposed participants to various modes of effective osteoporosis preventive exercise. The 30 participant target was met with 35 attendees completing the post-intervention measure. Participants evaluated the intervention very favorably. Seventy eight percent of women $(n=21)$ who initially responded to the study but did not attend the intervention listed location, date and time as the majority of their barriers. Additional events with alternative dates, times and locations may decrease this barrier as the majority indicated strong interest and desire to attend. Twelve exercise specialists provided a wide variety of vendor displays and ten registered nurses voluntarily participated to validate assessments and improve participant outcomes. Community support and resources are available to hold similar future events.

\section{Discussion}

Effective strategies to promote exercise are needed for higher risk women to protect the health of these vulnerable populations most at risk for osteoporosis fractures. The study 
literature review conclusion that theoretically informed interventions are more effective in changing health behaviors than those developed without theoretical basis and that very few studies have been conducted to ascertain how to motivate persons at risk for osteoporosis to engage in exercise to reduce or prevent osteoporosis was the basis for conducting this HBM guided intervention.

The nurse plays a vital role in health promotion as an important determinant of both health and welfare of the patient. The advanced practice nurse is most valuable in guiding both general practice nurses and assisting intra-professional practitioners to explore the interactive methods of a HBM guided intervention designed to improve self-efficacy for self-management osteoporosis exercise preventive behaviors.

This study designed by a Doctor of Nursing candidate and conducted in a community women's health facility that supports health promotion programs met the study purpose. The BE fracture FREE intervention modeled by the literature review's Qi et al. (2011) study utilized self-efficacy strategies to impact individual capability to perform a course of action to attain a desired outcome. Similar Qi et al. (2011) strategies to set small individual exercise goals that support success, verbal persuasion tactics, including role models and significant others were emphasized plus holding the activities in a social setting and including peers resulted in this study's significant individual self-efficacy improvement.

Although there is a generalization limitation due to the convenience sample, this study does demonstrate positive changes in self-efficacy for exercise in an aging woman population and may be useful in informing clinical practice. Although the sample size was small, the findings were statistically significant, and at minimum, provide validation for further investigation into the viability of on-going exercise bone health promotion intervention in the community. Further studies using larger sample sizes, ongoing support 
and longer outcome measure times are warranted to continue to explore osteoporosis preventive exercise behaviors particularly given the mounting importance to strive for disease prevention and management. Multi-dimensional strategies of promoting osteoporosis preventive exercise behaviors and supporting positive change are in the best interest of our healthcare organizations, providers, and patients. Understanding the influence of educational and motivational programs promoting exercise prevention behaviors is pertinent to the growing endeavor of improving enthusiasm among aging women to engage in effective bone health exercise. Improving motivation levels and educating people on osteoporosis remains paramount in disease prevention. If a patient's perceptions, beliefs, behaviors and levels of knowledge could be understood, then an advanced practice nurse could positively influence the triggers that drive self-efficacy to engage in osteoporosis exercise prevention behaviors. 


\section{Section V}

\section{Manuscript}

Exercise for Osteoporosis Prevention: A Health Belief Model Guided Intervention Corresponding Author: Hilda Amalia Taylor DNPc RN CNS

James Madison University Department of Nursing

MSC 4305

Harrisonburg, Virginia

22840

Taylorha@jmu.edu

5403833200

Fax: 5405687896 


\section{Abstract \\ Exercise for Osteoporosis Prevention: A Health Belief Model Guided Intervention}

Aim: To evaluate the feasibility of conducting a health fair, on bone health, as an intervention to improve the participants' report of their self-efficacy before and after their participation. Framework: The Health Belief Model (HBM) provides a useful framework to understand health behavior and engage people in preventive activities.

Design: A post- minus pre-intervention measure design.

Research question: Will participants in an osteoporosis exercise prevention targeted health fair significantly improve their osteoporosis self-efficacy exercise scores?

Method: Outcome HBM measures used: Revised Osteoporosis Knowledge Exercise Test (OKT), Osteoporosis Health Belief Exercise Scales (OHBS) and Osteoporosis Self-efficacy Exercise Scale (OSES), to gauge knowledge, beliefs and self-efficacy for exercise prevention behaviors in a convenience sample population. The exercise promotion health fair intervention was designed to strengthen self-efficacy for osteoporosis exercise prevention behaviors and outcome expectations. The HBM guided health fair was a two hour program lead by an advanced practice nurse who collaborated with community healthcare and fitness professionals. Results: Sixty two participants were screened for their ten year fracture risk probability and assessed to have $\mathrm{a} \geq 10$ score indicating significant risk. They completed pre-program measures and were invited to attend the intervention. Thirty five participants attended BE fracture FREE and completed the post-intervention OSES scale.

Conclusions: Participant total OSES mean scores for the post- minus pre-program were 26.00 vs 22.46. A paired, two-tailed $t$-test result of $p<0.001,<0.05$ preset alpha, indicated levels of self-efficacy for exercise prevention behaviors significantly improved following the health fair on bone health. 


\section{Exercise for Osteoporosis Prevention: A Health Belief Model Guided Intervention Introduction}

To attain high-quality, longer lives free of preventable disease, disability, injury and premature death, is a construct in the Healthy People 2020 overarching goals (Center for Disease and Prevention, CDC, 2020). Initiatives specify a national health objective to reduce the prevalence of osteoporosis, a disease marked by reduced bone strength leading to an increased risk of fractures. Osteoporosis is best prevented than treated. Fragility fractures result from a fall from a standing height or less, or present in the absence of obvious trauma. They are a serious osteoporosis complication due to underlying fragile bone that significantly decreases the ability to participate in physical activity, or even basic activities of daily living, and negatively impacts general quality of life (National

Osteoporosis Foundation, NOF, 2014). A Healthy People 2020 goal is to prevent illness and disability related to osteoporosis. General lifestyle modification advice that promotes bone health should be offered to all, and most urgently, to those at higher risk for fragility fractures.

Additionally, Healthy People 2020 promotes improving the health, function, and quality of life of older adults (CDC, 2020). Adults over sixty-five years of age are among the fastest growing age groups at higher risk for osteoporosis fracture risks compounded from falls (NOF, 2014). Falls can cause moderate to severe injuries, such as fractures, which significantly increase mortality. Fortunately, falls remain a largely preventable public health problem. A national health objective from Healthy People 2010 is still to increase to $30 \%$ the proportion of adults who perform physical activity that enhances and maintains muscular strength and endurance more than two days per week (CDC, 2011). Older adults stay independent and reduce their chances of falling through regular exercise. The most 
significant exercises focus on increasing leg strength and improving balance, while the exercises become more challenging over time (Christmas \& Anderson, 2000).

Osteoporosis prevention, coupled with reduced fall risk factors aimed at reducing fragility fracture risk, includes early prevention and exercise. Unfortunately, data from the National Health Interview Survey (NHIS) indicates less than twenty percent of older adults engage in enough physical activity, and less than six percent do weight bearing and strength training exercise recommended for bone health (Morbidity \& Mortality Weekly Report, 2004). Christmas and Anderson (2000) encourage health care providers to promote a less sedentary life style for older clients. Aging women in particular, with additional fracture risks, such as previous fracture and major fracture parental history, have an even more urgent need for preventive exercise behavior change (NOF, 2014).

\section{Background and Significance}

Osteoporosis is a common and serious bone disorder in aging women characterized by low bone mass and reduced bone strength that is diagnosed by bone mineral density (BMD) levels as defined by the World Health Organization (WHO, 2004). Osteoporosis is a disease in which the net loss of bone surpasses bone formation and is associated with aging. Osteoporosis increases the risk of fractures in older adults that are caused mostly by falling. Typically, osteoporosis goes undiagnosed until a fracture occurs, at which point the disease is already advanced and poses risks of further fractures (Snelling, Crespo, Schaeffer, Smith, \& Walbourn, 2001). As a result early screening and preventive intervention is crucial.

Osteoporosis is a public health issue of growing concern worldwide, with approximately 9 million fractures (Sadat-Ali \& Al-Turki, 2012). Osteoporosis has widespread economic and health impacts. Osteoporosis and osteoporotic fracture complications cause large numbers of disabilities, death, and significant health care costs 
through hospital and rehabilitation expenses (Iannidis, et al., 2009). Although arguably significant strategies including exercise have been proposed in the prevention of osteoporosis, only a few people have engaged in exercise preventive activities. Additionally, risk factors remain, which are beyond change; age, gender, and ethnicity. More women than men are at risk of osteoporosis, with the risk increasing significantly during the postmenopausal period for women, when the majority of fractures are diagnosed (Sadat-Ali \& Al-Turki, 2012). Of the 10 million Americans estimated to have osteoporosis, 8 million are women (NOF, 2014). Caucasian women have a higher incidence of osteoporosis than any other racial or ethnicity groups in the United States (U.S.) (Johnson, McLeod, Kennedy, \& McLeod, 2008). Additionally, each fragility fracture event is associated with a significantly increased risk of subsequent fractures compounded by the presence of any additional risk factors (Kemmler, HÃberle \& von Stengel, 2013).

Given the fact that the U.S. population is aging, the U.S is expected to have 14 million osteoporosis cases and more than 47 million Americans with low bone mass, a risk factor of osteoporosis, by 2020 (NOF, 2014). This is an indication that special attention should be given to the prevention of osteoporosis, which starts with identifying for each individual the knowledge and beliefs about osteoporosis and the associated behaviors one has to engage in to reduce their risk of osteoporosis. The NOF 2014 notes the disease remains to be a significant public health threat with approximately 1.5 million fractures each year, and estimates costs to be $\$ 17$ billion annually.

Osteoporosis is a serious threat to the independence, quality of life, and life of postmenopausal women (Estok, Sedlak, Doheny, \& Hall, 2008). Werner (2005), after a comprehensive review of osteoporotic knowledge literature, called on researchers to expand osteoporotic knowledge so as to enhance preventive programs and early diagnosis of 
osteoporosis. Ford and colleagues agreed and noted that the understanding and knowledge that a population has about a disease is a key component of ensuring that effective programs are developed (Ford, Bass \& Zhao, 2011).

\section{Theoretical Framework}

The Health Belief Model (HBM) is a conceptual framework that conceptualizes health behavior and possible reasons for behavioral choices with recommended health action (Turner, Hunt, DiBrezzo, \& Jones, 2004). The HBM is an individual level theory and explains the reason and under what conditions individuals take preventive actions (Estok et al., 2008). The HBM is the most-used theory in health education programs and promotion of healthy living (Nguyen, 2014).

In light of this original underlying assumption, the HBM helps in determining whether individuals are susceptible to a disease, and if so, theorizes whether the benefits they attach to the prevention of the disease are influential to their readiness to act. The HBM has seven constructs used individually or together to explain health behavior.

\section{Purpose of Study}

The proposed study goal was to promote osteoporosis prevention exercise behaviors among populations at higher risk by assessing the knowledge, beliefs, and self-efficacy of risk screened postmenopausal women. Guided by HBM constructs (Rosenstock, Stretcher \& Becker, 1988), the study measured knowledge, beliefs and self-efficacy for exercise prevention behaviors in a sample population. The underlying assumption of the proposed study is that sufficient osteoporosis knowledge mediated by attitudes, beliefs and selfefficacy for bone health exercise preventive behaviors are driving factors in the management of osteoporosis.

To assess higher risk screened postmenopausal women's baseline knowledge, beliefs 
and self-efficacy scores of osteoporosis self-managed exercise prevention behaviors was the first aim. To assess and compare pre- and post-intervention Osteoporosis Self-Efficacy Scores (OSES) and analyze the difference was the primary aim. To explore the effectiveness and feasibility of an osteoporosis exercise prevention health fair targeted for improving self-efficacy and engagement in preventive exercise was the final aim.

\section{Research question}

Will participants in an osteoporosis exercise prevention targeted health fair significantly improve their OSES score?

\section{Hypothesis}

Participants who participate in an osteoporosis exercise prevention targeted health fair will have significantly improved OSES scores compared to their baseline scores before the intervention.

\section{Review of the Literature}

A review of the theoretical and empirical literature on osteoporosis knowledge, beliefs, and behaviors and how this literature relates to the HBM is the basis for this literature review. Nguyen (2014) notes the HBM is a useful conceptual framework to understand osteoporosis exercise prevention behavior and associates the likelihood of engaging in recommended exercise to its constructs.

The review was limited to fifteen osteoporosis or fragility fracture studies published within five years, due to the abundance of relevant trials. The descriptive or interventional studies included were restricted to HBM or Self Efficacy theory guided studies that examined populations of adult women with a mean age greater than 45 years. The focus of the review search was for articles that utilized instruments and study design that noted: osteoporosis knowledge and beliefs including susceptibility, seriousness, benefits, barriers 
and self-efficacy of exercise and preventive health motivation potential. HBM guided osteoporosis instrument measures, Osteoporosis Knowledge Test (OKT), Osteoporosis Health Belief Scale (OHBS) and Osteoporosis Self-Efficacy Scale (OSES) were key variables in studies incorporated in the review.

\section{Discussion}

The main conclusion from the literature review is that very few studies have been conducted to ascertain how to motivate persons at risk for osteoporosis to engage in exercise to reduce or prevent osteoporosis. Osteoporosis disease prevention and reduction involves engaging target populations in regular exercise that is weight bearing and muscle strengthening in nature (NOF, 2014). However, the percentage of the higher risk target group that engages in preventive exercise is low.

Previous studies suggest that perceived susceptibility to and perceived severity of osteoporosis varied and requires individualized osteoporosis knowledge, beliefs and selfefficacy assessment prior to creating and implementing an intervention to alter osteoporosis exercise prevention behaviors. Perceived benefits of and barriers to, plus self-efficacy for osteoporosis exercise prevention behaviors, were demonstrated to be modifiable. Knowledge of osteoporosis is only general, which suggests the need of increased promotion and esteem for efficacious osteoporosis exercise prevention behaviors. Therefore, altering osteoporosis knowledge, beliefs and self-efficacy can increase osteoporosis exercise prevention behaviors.

The HBM framework can provide guidelines for program development allowing planners to understand, address and predict reasons for non-compliance. Tailoring interventions to address knowledge, beliefs and self-efficacy perceptions that impact the exercise behaviors of higher risk postmenopausal women's health beliefs is necessary to 
change behavior. One must consider these issues when planning interventions or promoting health behaviors that may help improve osteoporosis exercise prevention behaviors. In addition, there are modifying factors that can effect behavior compliance. Modifying factors would include media, health professionals, personal relationships, incentives, and selfefficacy of recommended health action. Effective strategies to promote exercise are needed for higher risk women to protect the health of these vulnerable populations most at risk for osteoporosis fractures.

Barriers impede a person's potential to engage in beneficial exercise routines that specifically target osteoporosis prevention and self-management (Qi et al., 2011). The most common barrier is the lack of self-efficacy, which is one's belief in his/her ability to succeed in specific situations. Many thought processes, emotional states, and patterns of behavior determine a person's level of motivation and will power to self-regulate. In this study, selfefficacy levels determine whether an at-risk osteoporosis participant can achieve the ability to engage in osteoporosis preventive behaviors (Qi et al., 2011). In additional to selfefficacy levels influence an individual's ability to prevent disease complications, but knowledge of the disease and a person's core beliefs determine how they view the threat of severity of osteoporosis (Nguyen, 2014). Improving motivation levels and educating people on osteoporosis remains paramount in disease prevention. If a patient's perceptions, beliefs, behaviors and levels of knowledge could be understood, then a health-care provider could discover the triggers that drive self-efficacy to engage in osteoporosis exercise prevention behaviors.

McLeod and Johnson (2011) conclude that theoretically informed interventions are more effective in changing health behaviors in practice than those developed without theoretical basis. By considering the most common osteoporosis exercise prevention health 
beliefs, such as benefits to, barriers for and self-efficacy, when planning education interventions, we may better address the factors that lead to health behavior change therein, improving prevention and management of osteoporosis.

\section{Implications for Capstone Project}

Health promotion interventions for higher risk women that combine exercise modalities with education and customized motivation support are limited in the literature. Many exercise trials for women at higher risk for fragility fracture do not incorporate individualized exercise counseling, and many educational intervention trials do not incorporate supervised exercise support. Studies that followed participation in a pilot health promotion program, where subjects had meaningful improvements in self-efficacy, and intention to initiate new exercise are lacking.

Pilot studies are an important first step with a new intervention to identify barriers and issues to address before implementing a larger study. The study feasibility, effectiveness and outcome results will increase knowledge of a vulnerable high risk population's exercise barriers. Such knowledge will assist intra-professional practitioners to explore the interactive methods of a HBM guided intervention designed to improve selfefficacy for self-management osteoporosis exercise preventive behaviors.

\section{Method}

\section{Research Design}

This study employed a pre-experimental, one-group pre and post-test design to evaluate the effectiveness and feasibility of a targeted osteoporosis exercise intervention.

\section{Description of the Sample}

The convenience sample was comprised of postmenopausal women independently living in a community hospital service area. Volunteering and consenting women who met 
study inclusion criteria were screened. Those who scored $\geq 10 \%$ fracture risk on the Fracture Risk Assessment Tool (FRAX®) were invited by the principal investigator to participate in the initial survey measures. A study goal minimum of thirty participants who met intervention inclusion criteria and completed the initial study survey measures were invited to participate in the intervention.

Inclusion criteria: postmenopausal women (50+ years of age), English speaking, FRAX ${ }^{\circledR}$ screened $\geq 10 \%$ osteoporotic fracture risk score (over four weeks), and completed study baseline survey measures (over four weeks).

Exclusion criteria: Medical restrictions prohibiting preventive exercise.

\section{Setting}

The study was conducted at a community hospital medical center, a 238-bed acute care facility located in northwestern Virginia, which is an affiliate of a nonprofit healthcare organization and serves a seven county area with a population of close to 218,000 . The stated mission of the hospital is to "improve the health status of the community by maintaining, enhancing and restoring personal health and well-being." Specialty service divisions relative to the study include an Orthopedic and Sports Medicine Center (diagnostic and treatment), a Women's Center (bone density testing, special events, education and support), and a Wellness Center (medical-based fitness). Additional services include acute inpatient and outpatient rehabilitation including specialty certified therapists in women's health and the Senior Advantage membership program promoting community health.

\section{Program}

The osteoporosis self-management BE fracture FREE exercise promotion health fair intervention was designed to strengthen self-efficacy for osteoporosis exercise prevention behaviors and outcome expectations. The HBM guided exercise promotion health fair was a 
two hour program lead by an advanced practice nurse collaborating with community healthcare and fitness professionals. BE fracture FREE was held in a community education convention area located in the health system's women's center. Registered nurses initially interviewed, measured and weighed participants. Each applicant was FRAX® assessed, given their printed assessment and encouraged to review their results with health care providers.

Educational components included a review of materials from the National Osteoporosis Foundation (NOF) relevant to effective exercise intervention, with emphasis on discussion and application of the information. The seriousness of and susceptibility to developing osteoporosis and recommended health measures was discussed with the audience. The benefits and barriers of exercise was the focus. Participants were encouraged to ask questions and express concerns. Following the initial program, participants viewed individual vendor displays that presented exercise modalities available in the community. Experts showcased a variety of exercise prevention methods proven effective for osteoporosis self-management. Additionally, the program included age relevant role models who demonstrated exercise and engaged participants in a variety of bone health methods (i.e. Tai Chi, mountain biking, Golden Zumba, Nia, resistance training, balance and flexibility training, aerobic dance, Pilates, brisk walking, and hiking). Participants were encouraged to share with others their lived experience with exercise success and fracture history. Strategies were directed at changing attitudes, through self-monitoring, presenting exercise as an enjoyable process, setting goals regarding exercise, and increasing knowledge regarding the need and importance of exercise behaviors. Participants were coached to set small individual goals for exercise that could be mastered so they may experience success. Current physical activity levels were incorporated in individualized goals. Participants were 
encouraged to make small improvements toward an effective goal of exercise, three times per week, 20-30 minutes of weight bearing and resistive training exercise.

\section{Procedures}

Figure 1 maps the study's participant enrollment, screening, measures, intervention, allocation, follow up and analysis. The principal investigator developed and displayed a recruitment brochure that described the study in service areas of the community hospital health system. Potential participants voluntarily contacted the principal investigator and provided their FRAX® screening information. Over a four week data collection time, the principal investigator screened and invited study participants who met qualifying intervention criteria to complete three forms: a written consent, demographic questionnaire and baseline survey measures. To achieve the initial study aim, the principal investigator assessed participants' baseline knowledge, beliefs and self-efficacy for osteoporosis selfmanagement exercise prevention behaviors using the revised Osteoporosis Knowledge (OKT) exercise subscale, Osteoporosis Health Belief Scale (OHBS) exercise subscale and Osteoporosis Self-Efficacy Scale (OSES) exercise subscale instrument scores. The overall knowledge of risk factors, beliefs about exercise, and barriers to engaging in bone health promotion behaviors was analyzed by the investigator. The results were utilized to tailor an exercise health promotion fair intervention to improve participant exercise self-efficacy.

To achieve the second study aim, the principal investigator assessed and compared pre- and post-intervention participant OSES instrument scores to determine if the intervention significantly improved osteoporosis self-efficacy exercise scores. The intervention participant's self-efficacy for exercise engagement and outcome was assessed. The OSES pre- and post-intervention results were compared.

The final study aim, to investigate the effectiveness and feasibility of a health fair 
designed for improving self-efficacy for engagement in preventive exercise, was achieved by analyzing the intervention follow-up outcome variables. Over a two-week time, the principal investigator contacted study participants who failed to attend the intervention and identified their reported barriers. Intervention participants were contacted over a two week follow up time to identify their reported change in self-efficacy and current barriers for engaging in osteoporosis exercise prevention behaviors. The investigator determined participant response to identify whether they engaged in exercise activities that may enhance bone health and hence reduce osteoporosis complications

\section{Measures}

Study instruments were utilized to collect data on the study variables. The questionnaires are standardized, valid and reliable instruments (McLeod \& Johnson, 2011). The measures relate to the HBM constructs and are validated in prior studies (Nguyen, 2014).

World Health Organization (WHO) Fracture Risk Assessment Tool (FRAX®): The FRAX ${ }^{\circledR}$ Calculator is an online fracture risk assessment measure that can calculate an individual's 10-year risk of fracture (WHO, 2008). The FRAX® calculator is used to generate a numeric value for the likelihood of developing a major osteoporotic fracture or a hip fracture in the next 10 years. FRAX® is easily accessed at the following website: http://shef.ac.uk/FRAX/tool.aspx?country=9

Demographic Survey: Socio-demographic items include a self-report of descriptive information pertinent to osteoporosis risks. Categories include: initials, two contact numbers or emails, age, gender race/ethnicity, age of menopause, current physical activity and personal health history information.

Osteoporosis Knowledge Test (OKT): The OKT developed by Kim and colleagues 
(1991) and revised (2012) measures the extent of osteoporosis knowledge a person has. Subjects rated the 6 exercise item subscale that pertained to knowledge of exercise as a preventive behavior for osteoporosis.

Osteoporosis Health Belief Scale (OHBS): Several studies have used the OHBS or subscales to assess osteoporosis beliefs (Nguyen, 2014). The modified OHBS scale utilized in this study consists of two OHBS subscales, benefits and barriers to exercise.

Osteoporosis Self-Efficacy Scale (OSES): The OSES is used to measure subject self-efficacy, or the confidence one has in performing the exercise behaviors specifically related to osteoporosis prevention (Gendler et al., 1991). The self-efficacy for exercise, measured by the use of six exercise subscale items, measures an individual's confidence at various levels of an exercise program, including the commencement of a new exercise, changing habits of an exercise, applying appropriate effort in the exercise, completion of difficult exercises, time involvement, and the individuals' compliance with the recommended exercise (Swaim et al., 2008). Higher scores on the OSES scale imply that the participant believes in one's ability to successfully complete exercise programs.

\section{Protection of Human Subjects}

This proposal was approved by the Institutional Review Board (IRB) of the facility utilized for recruitment and intervention. Participants signed an informed consent prior to participating in the study.

\section{Results}

The capstone study was implemented over an eight week timeframe to assess the higher risk FRAX® screened participants' knowledge, beliefs and self-efficacy for osteoporosis self-managed prevention exercise behaviors. Following IRB approval, 
promotional and recruitment brochures were distributed in the medical center service areas and in local public advertising locations.

The sample population consisted of 111 women who responded and were FRAX® screened. Forty nine were excluded who scored $<10 \%$ risk or declined to participate further. Sixty two consented to participate in the study, all of whom completed the preintervention measures. Additionally, these 62 women were invited and encouraged to attend the BE fracture FREE intervention held June 23, 2015. All potential study participants were invited to the public health promotion intervention regardless of eligibility to participate in the study.

Of the women who attended the health promotion BE fracture FREE program, 35 who represented $56 \%$ of the original sample of 62 completed both the pre- and postintervention measures. Twenty seven who represented $44 \%$ of the sample did not attend, as they had barriers categorized as date and time conflicts, location, and lack of interest or were not able to be contacted. Figure 4 consort diagram of the study flow illustrates the participant outcomes.

Registered nurses verified each participant's FRAX® score by measuring their height and weight. Additionally, they interviewed each participant and reviewed their individual risk factors. Participants received a copy of their individual FRAX® assessment and were advised to share their results with health professionals. Study participants received bone health information and encouragement during the program from professional exercise specialists and registered nurses.

Osteoporosis disease information was presented with risk factors and diagnosis criteria emphasized. Only one participant was able to identify their personal Dual-energy Xray Absorptiometry (DEXA) T-score and subsequent osteoporosis diagnosis while several 
women acknowledged they knew they possessed an osteoporosis diagnosis but were unaware of their T-score. Osteoporosis diagnosis was not an inclusion criteria for participation in this study, as women with high FRAX® risk scores may not be diagnosed or have knowledge of disease presence. All women regardless of an osteoporosis diagnosis were recruited for their bone health intervention potential.

The descriptive analysis of demographic and FRAX® risk characteristics are displayed in Table 1. Non-modifiable fracture risk factors include gender, race/ethnicity and parental fracture history. The majority of aging women meeting inclusion criteria for the convenience sample were Caucasian. Fifty five (89\%) of the women were Caucasian and 7 (11\%) of the women were African American. There were no other racial or ethnic groups represented. Seventeen or $27 \%$ had increased risk due to their parental hip fracture history. Concomitant diagnosis of osteoporosis fracture or rheumatoid arthritis increased fracture risk. The study participants with rheumatoid arthritis totaled 11(18\%), and 23 (37\%) were identified with a previous fracture. Behaviors that contributed to the sample's higher screening scores included 17 (27\%) who smoke and 17 (27\%) who consume alcohol daily. Preventive physical exercise decreased risk scores. Fourteen (23\%) total participants reported exercise; but only $9(14 \%)$ participants identified compliance with the recommended frequency of $>3$ times a week.

The two independent groups, the group that attended BE fracture FREE $(n=35)$ and the group that did not attend $(n=27)$ were compared using the exact chi-square test for categorical variables and an independent $t$-test for continuous variables. Only the weight was found to be statistically significant $\mathrm{p}<0.05$ preset alpha. The bone health fair participants mean weight was 11.72 pounds lower than the mean weight of the group that did not attend. No distinguishing features between groups were identified to warrant 
additional intervention target objectives. Additionally, no group differences were noted to contribute to the barriers to attending the intervention.

Table 2 outlines the pre-intervention participants $(\mathrm{N}=62)$ OKT results. The total score mean was 3.31(SD 1.62) and responses ranged 0-6 of a possible 0-6 score. Four was the most frequent score, achieved by 19 individuals, who totaled $31 \%$. The majority of participants chose aerobic dancing as the best for reducing a person's chances of developing osteoporosis. This was the higher percentage correct item answer chosen in the scale. The sample of individuals who answered it correctly totaled 47 which equaled $76 \%$. Question 1, to strengthen bones, it is recommended that a person exercise at a moderately intense level for 30 minutes a day at least 5 days a week was answered correctly by 20 individuals, comprising 32\%, and noted as the lower correct item answer chosen in the scale. All other items had a correct score $\geq 50 \%$ with scores ranging from $50 \%-61 \%$. The OKT 3.31 (SD 1.62) mean score indicates median knowledge about exercise effects on osteoporosis and therefore engagement potential in preventive exercise behaviors may improve with additional knowledge interventions.

The group that attended BE fracture FREE and the group that did not attend OKT mean scores were statistically analyzed for differences using an independent $t$-test. Three individual questions plus the total score were statistically significant with $\mathrm{p}<0.05$ preset alpha. The group that did not attend the intervention scored a higher mean on each of three individual OKT questions, (\#2) 0.44 higher, (\#4) 0.74 higher and (\#5) 0.77 higher but overall scored 0.87 lower on the total measure mean score. Groups' OKT mean scores, 3.69 (SD 1.28), 2.82 (SD 1.88) and 3.31 (SD 1.62) were middle range of the possible 0-6 score, thereby, leaving room for knowledge growth. The tailored knowledge information presentations and reinforcements pertinent to the participant knowledge deficits were key 
intervention design components. BE fracture FREE was planned to include both NOF knowledge handouts, on site information, and health and exercise professionals to demonstrate exercise modes and encourage individuals to engage in recommended exercise methods. Refer to Appendix F for a list of OKT questions and Figure 3 for a description of the intervention.

Table 3 outlines the pre-intervention participants $(\mathrm{N}=62)$ OHBS results. Each item is scored on a 5-point scale, with a total score ranging from 1-30 for each subscale. The benefits of exercise total participant mean score was 25.05 (SD 2.71), and ranged 19-30; while the barriers to exercise total participant mean score was 16.45 (SD 4.16) and ranged 624. Pre-intervention individuals $(\mathrm{N}=62)$ completed two subscales designed to measure their perceived beliefs related to specific exercise behaviors in the prevention of osteoporosis. The cumulative results of the benefits of exercise items indicate study individuals agree to strongly agree that they feel positive about exercise and believe that regular exercise benefits osteoporosis prevention. Study results indicate individuals' are cumulatively neutral on items showing they have mental and physical ability to engage in regular exercise, time and facilities for exercise. Results indicate strong disagreement that family discouragement was a barrier to exercise. Benefits scores indicate individuals' value exercise and support an intervention opportunity to improve exercise behaviors while barriers scores are more neutral indicating less potential for obstacles to impede exercise behaviors.

The group that attended BE fracture FREE and the group that did not attend OHBS mean scores were compared using an independent $t$-test. Comparing the groups for differences on the barriers subscale indicates no significant results. Benefit subscale question \#3 plus the total benefits mean scores indicate statistical significance with $\mathrm{p}<0.05$. The group that attended the intervention scored a 0.33 higher mean on the OHBS benefit 
question \#3 and overall scored 1.47 higher on the total measure mean result. Groups' OHBS mean scores, 25.69 (SD 2.36), 24.22 (SD 2.94) and 25.05 (SD 2.71) indicate higher ranges of the possible 1-30 score, thereby, supporting study individuals believe there are benefits of achieving the recommended exercise activity. The significant pre-intervention higher score in the group who attended the intervention may indicate a superior believe in the benefits of preventive exercise behaviors that motivated them to attend. Refer to Appendix G for a list of OHBS questions.

In order to assess and compare post- minus pre-intervention osteoporosis selfefficacy scores, intervention attendees completed a post-intervention osteoporosis selfefficacy scale. Table 4 outlines the total pre- $(\mathrm{N}=62)$, post-intervention $(n=35)$ and nonattendance $(\mathrm{n}=27)$ participants' OSES results. Each item was scored on a 5-point scale from 1 ("strongly disagree") to 5 ("strongly agree"). The 6 measured exercise subscale items indicate the individuals' confidence at various levels of an exercise program including the commencement of a new exercise, changing habits of an exercise, and applying appropriate effort in the exercise, completion of difficult exercises, time involvement, and their compliance with recommended exercise. Higher scores imply that the participant believes they have the ability to successfully complete recommended exercise programs. The study total participant pre-intervention results indicate individuals chose agree to strongly agree on all items, with a 20.94 (SD 4.81) mean total score comprising $69 \%$ of the potential score. Therefore, the baseline confidence level was positive and provided a promising motivational platform to build on. The measured pair participants' pre-intervention scores were similar to the whole sample with a 22.46 (SD 4.28) mean total score comprising $75 \%$ of the possible score percentile. The post-intervention scores were significantly more positive with a 26.00 (SD 2.81) total mean score comprising $87 \%$ of the feasible score. This 3.54 (SD 2.72) 
increase in the total mean score for matched pairs $(n=35)$ indicates a $12 \%$ improved osteoporosis self-efficacy for exercise result.

Assumptions for the paired, 2-tailed $t$-test were met with two paired OSES measurements, a continuous level dependent variable and normal distribution results. Postand pre-intervention paired measures were calculated and the self-efficacy score differences between two related observations were compared. IBM® SPSS ${ }^{\circledR}$ version 22 computed a 2 tailed significance of $p<0.001,<0.05$ preset alpha; therefore the hypothesis that those participating in an osteoporosis exercise prevention targeted health fair will significantly improve OSES scores compared to their baseline scores is supported. The difference in mean OSES scores between the post-intervention minus the pre-intervention scores is significantly different, therefore the difference in perceived self-efficacy before and after BE fracture FREE is evaluated as significant. The total score mean difference between postand pre-intervention scores was 3.54 (SD 2.72). We are confident that $95 \%$ of the time, the true difference in mean scores will be between 2.17 and 4.34 points.

The group that attended BE fracture FREE and the group that did not attend preOSES mean scores, 22.46 (SD 4.28) and 19.11(SD 5.06) were statistically analyzed for differences using an independent $t$-test. The pre-fair group's comparison indicated significant differences with $\mathrm{p}<0.05$ preset alpha. The group that attended the intervention scored a 3.54 (2.72) higher mean on the pre-OSES total measure result. The group's significantly lower mean score who did not attend the intervention may reflect their low motivation to engage in exercise and therefore a related lack of motivation to attend an intervention. All potential study individuals were encouraged to attend the public BE fracture FREE intervention. General public promotion advertisements also notified target population individuals. Refer to Appendix $\mathrm{H}$ for a list of OSES questions. 
At two weeks post intervention participants were contacted and they reported their results as: 19 made changes in their exercise behaviors, 5 set new goals for change and 2 initiated new exercise programs while 16 made no changes.

The study showed that this community exercise fair aimed at improving self-efficacy for exercise in higher fracture risk aging women was feasible and effective. One's selfefficacy to exercise could be influenced by a two hour bone health fair that exposed participants to various modes of effective osteoporosis preventive exercise. The 30 participant target was met with 35 attendees completing the post-intervention measure. Participants evaluated the intervention very favorably. Seventy eight percent of women $(n=21)$ who initially responded to the study but did not attend the intervention listed location, date and time as the majority of their barriers. Additional events with alternative dates, times and locations may decrease this barrier as the majority indicated strong interest and desire to attend. Twelve exercise specialists provided a wide variety of vendor displays and ten registered nurses voluntarily participated to validate assessments and improve participant outcomes. Community support and resources are available to hold similar future events.

\section{Discussion}

Effective strategies to promote exercise are needed for higher risk women to protect the health of these vulnerable populations most at risk for osteoporosis fractures. The study literature review conclusion that theoretically informed interventions are more effective in changing health behaviors than those developed without theoretical basis and that very few studies have been conducted to ascertain how to motivate persons at risk for osteoporosis to engage in exercise to reduce or prevent osteoporosis was the basis for conducting this HBM guided intervention. 
The nurse plays a vital role in health promotion as an important determinant of both health and welfare of the patient. The advanced practice nurse is most valuable in guiding both general practice nurses and assisting intra-professional practitioners to explore the interactive methods of a HBM guided intervention designed to improve self-efficacy for self-management osteoporosis exercise preventive behaviors.

This study designed by a Doctor of Nursing candidate and conducted in a community women's health facility that supports health promotion programs met the study purpose. The BE fracture FREE intervention modeled by the literature review's Qi et al. (2011) study utilized self-efficacy strategies to impact individual capability to perform a course of action to attain a desired outcome. Similar Qi et al. (2011) strategies to set small individual exercise goals that support success, verbal persuasion tactics, including role models and significant others were emphasized plus holding the activities in a social setting and including peers resulted in this study's significant individual self-efficacy improvement.

Although there is a generalization limitation due to the convenience sample, this study does demonstrate positive changes in self-efficacy for exercise in an aging woman population and may be useful in informing clinical practice. Although the sample size was small, the findings were statistically significant, and at minimum, provide validation for further investigation into the viability of on-going exercise bone health promotion intervention in the community. Further studies using larger sample sizes, ongoing support and longer outcome measure times are warranted to continue to explore osteoporosis preventive exercise behaviors particularly given the mounting importance to strive for disease prevention and management. Multi-dimensional strategies of promoting osteoporosis preventive exercise behaviors and supporting positive change are in the best interest of our healthcare organizations, providers, and patients. Understanding the 
influence of educational and motivational programs promoting exercise prevention behaviors is pertinent to the growing endeavor of improving enthusiasm among aging women to engage in effective bone health exercise. Improving motivation levels and educating people on osteoporosis remains paramount in disease prevention. If a patient's perceptions, beliefs, behaviors and levels of knowledge could be understood, then an advanced practice nurse could positively influence the triggers that drive self-efficacy to engage in osteoporosis exercise prevention behaviors. 


\section{References}

American College of Sports Medicine (ACSM). (2009) Guidelines for Exercise Testing and Prescription. Philadelphia, Pa: Lippincott Williams \& Wilkins.

Center for Disease Control and Preventions (CDC). (2020). Healthy People 2020, Arthritis, Osteoporosis and Chronic Back Conditions. Washington, DC. Retrieved from Centers for Disease Control and Prevention http://www.healthypeople.gov/2020/topicsobjectives2020/overview.aspx?topicid=3

Center for Disease Control and Prevention(CDC). (2011) Physical activity and health: The benefits of physical activity. Retrieved from Centers for Disease Control and Prevention:

http://www.cdc.gov/physicalactivity/everyone/health/index.html\#StrengthenBonesMus $\underline{\text { cle }}$

Christmas, C., \& Andersen, R. A. (2000). Exercise and older patients: Guidelines for the clinician. Journal of the American Geriatrics Society, 48(3), 318-324. Retrieved from $\underline{\text { http://search.ebscohost.com.proxy.its.virginia.edu/login.aspx } \text { ?direct }=\text { true } \& d b=0 f m \& A}$ $\underline{\mathrm{N}=511154736 \& \text { site }=\text { ehost-live\&scope }=\text { site }}$

Estok, P. J., Sedlak, C. A., Doheny, M. O., \& Hall, R. (2008). Structural model for osteoporosis preventing behavior in postmenopausal women. Nursing Research, 56(3)(May/June), 148-158. doi:00006199-200705000-00002

Ford, M., Bass, M., Zhao, Y., Bai, B., \& Zhao, Y. (2011). Osteoporosis knowledge, selfefficacy, and beliefs among college students in the USA and china. Journal of Osteoporosis, (Article ID 729219) doi:doi:10.4061/2011/72921

Gendler, P. E., Coviak, C. P., Martin, J. T., Kim, K. K., Dankers, J. K., Barclay, J. M., \& Sanchez, T. A. (2014). Revision of the osteoporosis knowledge test: Reliability and 
validity. Western Journal of Nursing Research, doi:0193945914537565 [pii]

Iloannidis, G., Papaioannou, A., Hopman, W. M., Akhtar-Danesh, N., Anastassiades, T., Pickard, L., Adachi, J. D. (2009). Relation between fractures and mortality: Results from the Canadian multicenter osteoporosis study. CMAJ: Canadian Medical Association Journal = Journal De l'Association Medicale Canadienne, 181(5), 265271. doi:10.1503/cmaj.081720

Johnson, S., McLeod, W., Kennedy, L., \& McLeod, K. (2008). Osteoporosis health beliefs among younger and older men and women. Health Education and Behavior, 35(5), 721-733. doi: 10.1177/1090198107301331

Kim, Tae-Hee, Lee, Young-Sang, Byun, Dong Won, Jang, Seyeon, Jeon, Dong-Su, Lee, Hae-Hyeog. (2013). Evaluation of the osteoporosis health belief scale in Korean women. Journal of Bone Metabolism, 20, 25-30. doi:10.11005/jbm.2013.20.1.25

Kim, K. K., Horan, M. L. \& Gendler, P., (1991). Development and evaluation of the osteoporosis health belief scale. Research in Nursing \& Health, 14(2), 155-163. doi:10.1002/nur.4770140210

Kemmler, W., HÃ berle, L., \& von Stengel, S. (2013). Effects of exercise on fracture reduction in older adults. Osteoporosis International, 24(7), 1937-1950. doi:10.1007/s00198-012-2248-7

Lee, Young-Shin., Baek, Jong-Duek., Yang, K., \& Yoon, S. (2012). Relationships between physical activity and awareness and treatment status among adults with low femoral bone density in the United States. American Journal of Health Promotion, 27(1), 2-9. Retrieved from: https://search-ebscohostcom.proxy.its.virginia.edu/login. aspx ?direct=true $\& d b=s 3 h \& A N=79757533 \&$ site $=$ ehost -live 
McLeod, K. M., \& Johnson, C. S. (2011). A systematic review of osteoporosis health beliefs in adult men and women. Journal of Osteoporosis, 2011, 197454. doi: $10.4061 / 2011 / 197454$

National Institutes of Health (NIH). (2014). Osteoporosis and related bone diseases national research center. Retrieved from National Institutes of Health: http://www.niams.nih.gov/Health_Info/Bone/default.asp

National Osteoporosis Foundation (NOF). (2014). Osteoporosis Report. Washington, DC. Retrieved from National Osteoporosis Foundation: http://nof.org/about/osteo-report Nguyen, V. H. (2014). An assessment of osteoporosis health beliefs based on the health belief model. International Journal of Health Promotion and Education, 52(2), 105115. doi:10.1080/14635240.2014.893138

Qi, B., Resnick, B., Smeltzer, S., \& Bausell, B. (2011). Self-efficacy program to prevent osteoporosis among Chinese immigrants. Nursing Research, 60(6), 393-404. doi:10.1097/NNR.0b013e3182337dc3

Rosenstock, I. M., Strecher, V. J., \& Becker, M. H. (1988). Social learning theory and the health belief model. Health Education Quarterly, 15(2), 175-183.

Sadat-Ali, M., \& Al-Turki, H. A. (2012). Genetic influence of candidate osteoporosis genes in Saudi Arabian population: A pilot study. Journal of Osteoporosis, 2012, 569145. doi:10.1155/2012/569145

Snelling, A., Crespo, C., Schaeffer, M., Smith, S., \& Walbourn, L. (2001). Modifiable and non-modifiable factors associated with osteoporosis in postmenopausal women: results from the third national health and nutrition examination survey, 1988-1994. Journal of Women's Health \& Gender-Based Medicine, 10(1), 57-65. doi:10.1089/152460901750076124 
Strength training among adults aged greater than/equal to 65 years -- United States, 2001. (2004). MMWR: Morbidity \& Mortality Weekly Report, 53(2), 25-28. Retrieved from http://search.ebscohost.com.proxy.its.virginia.edu/login.aspx?direct=true $\& d b=\operatorname{cin} 20 \& A$ $\underline{\mathrm{N}=2004053450 \& \text { site }=\text { ehost-live \&scope }=\text { site }}$

Swaim, R. A., Barner, J. C., \& Brown, C. M. (2008). The relationship of calcium intake and exercise to osteoporosis health beliefs in postmenopausal women. Research in Social and Administrative Pharmacy, 4(2), 153-163. doi:

http://dx.doi.org.proxy.its.virginia.edu/10.1016/j.sapharm.2007.03.004

Turner, L. W., Hunt, S. B., DiBrezzo, R., \& Jones, C. (2004). Design and implementation of an osteoporosis prevention program using the health belief model. American Journal of Health Studies, 19(2) doi: 1090-0500

Werner, P. (2005). Knowledge about osteoporosis: assessment, correlates and outcomes. International Osteoporosis Foundation and National Osteoporosis Foundation 2004, Volume 16(Issue 2), 115-127.

World Health Organization (WHO). (2008). Fracture Risk Assessment Tool (FRAX®). (C) World Health Organization Collaborating Centre for Metabolic Bone Diseases, University of Sheffield, UK, http://shef.ac.uk/FRAX/tool.aspx?country=9

World Health Organization (WHO). (2004). Scientific Group on the Assessment of Osteoporosis at Primary Health Care Level. Brussels, Belgium. Retrieved from World Health Organization: http://www.who.int/chp/topics/Osteoporosis.pdf 
Table 1

Summary of demographic and FRAX® risk characteristics

\begin{tabular}{|c|c|c|c|}
\hline & $\begin{array}{c}\text { Attended } \\
\text { Fair } \\
(\mathbf{n}=\mathbf{3 5}) \\
\end{array}$ & $\begin{array}{c}\text { Did not } \\
\text { Attend Fair } \\
(n=27) \\
\end{array}$ & $\begin{array}{r}\text { Total } \\
\text { Particip } \\
(\mathrm{N}=62 \\
\end{array}$ \\
\hline Characteristics & $\begin{array}{c}\text { Range } \\
\text { Mean (SD) }\end{array}$ & $\begin{array}{c}\text { Range } \\
\text { Mean (SD) }\end{array}$ & $\begin{array}{r}\text { Range } \\
\text { Mean (S) }\end{array}$ \\
\hline \multicolumn{4}{|l|}{ Objective Measures } \\
\hline Frax $®$ Score & $\begin{array}{c}10-45 \\
18.83(7.90)\end{array}$ & $\begin{array}{l}10-40 \\
16.96(7.39)\end{array}$ & $\begin{array}{l}10-45 \\
18.02\end{array}$ \\
\hline Age & $\begin{array}{c}55-87 \\
66.11(6.00)\end{array}$ & $\begin{array}{l}50-86 \\
68.15(8.86)\end{array}$ & $\begin{array}{l}50-87 \\
67.00\end{array}$ \\
\hline Menopause Age & $\begin{array}{c}32-56 \\
51.54(4.44)\end{array}$ & $\begin{array}{l}48-56 \\
53.11(1.97)\end{array}$ & $\begin{array}{l}32-56 \\
52.23\end{array}$ \\
\hline Weight (lbs.) & $\begin{array}{c}100-228 \\
147.17(27.13)^{2}\end{array}$ & $\begin{array}{l}92-239 \\
158.89(40.89)^{2}\end{array}$ & $\begin{array}{r}92-23 \\
152.27\end{array}$ \\
\hline \multirow[t]{2}{*}{ Height (cm) } & $\begin{array}{c}60-69 \\
64.66(2.43)\end{array}$ & $\begin{array}{l}61-68 \\
64.24(2.00)\end{array}$ & $\begin{array}{l}60-69 \\
64.48\end{array}$ \\
\hline & $\mathrm{n}(\%)$ & n $(\%)$ & $\mathrm{N}(\%$ \\
\hline \multicolumn{4}{|l|}{ Non-modifiable Factors } \\
\hline $\begin{array}{l}\text { *Female } \\
\text { Male }\end{array}$ & $35(100)$ & $27(100)$ & $\begin{array}{c}62(100) \\
0(0)\end{array}$ \\
\hline \multicolumn{4}{|l|}{ Race } \\
\hline $\begin{array}{l}\text { *Caucasian } \\
\text { African American } \\
\text { Asian } \\
\text { Hispanic }\end{array}$ & $\begin{array}{c}31(89) \\
411)\end{array}$ & $\begin{array}{r}24(89) \\
3(11)\end{array}$ & $\begin{array}{l}55(89) \\
7(11) \\
0(0) \\
0(0)\end{array}$ \\
\hline $\begin{array}{l}\text { Parent with Hip Fracture } \\
* \text { Yes } \\
\text { No }\end{array}$ & $\begin{array}{r}9(26) \\
26(74)\end{array}$ & $\begin{array}{r}8(30) \\
19(70)\end{array}$ & $\begin{array}{l}17(27) \\
45(73)\end{array}$ \\
\hline \multicolumn{4}{|l|}{ Concomitant Diagnosis } \\
\hline $\begin{array}{c}* \text { Yes } \\
\text { No }\end{array}$ & $\begin{array}{l}13(37) \\
22(63)\end{array}$ & $\begin{array}{l}10(37) \\
17(63)\end{array}$ & $\begin{array}{l}23(37) \\
39(63)\end{array}$ \\
\hline \multicolumn{4}{|l|}{ Rheumatoid Arthritis } \\
\hline No & $26(74)$ & $25(93)$ & $51(82)$ \\
\hline \multicolumn{4}{|l|}{ Risk Behaviors } \\
\hline $\begin{array}{c}* \text { Yes } \\
\text { No }\end{array}$ & $\begin{array}{l}10(29) \\
25(71)\end{array}$ & $\begin{array}{r}7(26) \\
20(74)\end{array}$ & $\begin{array}{l}17(27) \\
45(73)\end{array}$ \\
\hline \multicolumn{4}{|l|}{ Alcohol Consumption } \\
\hline $\begin{array}{l}\text { None } \\
\text { Occasional } \\
\text { *Daily }\end{array}$ & $\begin{array}{r}20(57) \\
8(23) \\
7(26)\end{array}$ & $\begin{array}{r}12(44) \\
5(19) \\
10(37)\end{array}$ & $\begin{array}{l}32(52) \\
13(21) \\
17(27)\end{array}$ \\
\hline
\end{tabular}


Engagement in Physical Exercise

\begin{tabular}{lrrr} 
Yes & $8(23)$ & $6(22)$ & $14(23)$ \\
$*$ No $<3$ times a week & $12(34)$ & $7(26)$ & $19(31)$ \\
$>3$ times a week & $6(17)$ & $3(11)$ & $9(14)$ \\
$*$ None & $9(26)$ & $11(41)$ & $20(32)$ \\
\hline
\end{tabular}

Note. *Characteristics and risk behaviors increasing Frax ${ }^{\circledR}$ Score

${ }^{1} \mathrm{p}<0.05$ for an exact chi-square test comparing those who attended BE fracture FREE and those who did not (no significant results noted in categorical variables)

${ }^{2} \mathrm{p}<0.05$ for an independent $t$-test comparing those who attended BE fracture FREE and those who did not (one significant result noted in weight variable) 
Table 2

Summation of Revised Osteoporosis Knowledge Test-Exercise (OKT) Scores

\begin{tabular}{|c|c|c|c|}
\hline & $\begin{array}{l}\text { Attended } \\
\text { Fair } \\
(\mathbf{n}=35)\end{array}$ & $\begin{array}{c}\text { Did not } \\
\text { Attend Fair } \\
(n=27)\end{array}$ & $\begin{array}{c}\text { Total } \\
\text { Participants } \\
(\mathrm{N}=62)\end{array}$ \\
\hline & $\begin{array}{c}\text { Range } \\
\text { Mean (SD) }\end{array}$ & $\begin{array}{c}\text { Range } \\
\text { Mean (SD) }\end{array}$ & $\begin{array}{c}\text { Range } \\
\text { Mean (SD) }\end{array}$ \\
\hline & $1-4$ & $1-4$ & $1-4$ \\
\hline \#1 OKT & $\begin{array}{c}2.60(0.88) \\
1-4\end{array}$ & $\begin{array}{c}2.41(1.08) \\
1-4\end{array}$ & $\begin{array}{c}2.52(.97) \\
1-4\end{array}$ \\
\hline \#2 OKT & $\begin{array}{c}1.97(0.71)^{1} \\
1-4\end{array}$ & $\begin{array}{c}2.41(0.97)^{1} \\
1-4\end{array}$ & $\begin{array}{c}2.16(0.85) \\
1-4\end{array}$ \\
\hline \#3 OKT & $\begin{array}{c}2.46(0.82) \\
1-4\end{array}$ & $\begin{array}{c}2.37(0.88) \\
1-4\end{array}$ & $\begin{array}{c}2.42(0.84) \\
1-4\end{array}$ \\
\hline \#4 OKT & $\begin{array}{c}2.26(1.01)^{1} \\
1-4\end{array}$ & $\begin{array}{c}3.00(1.00)^{1} \\
1-4\end{array}$ & $\begin{array}{c}2.58(1.06) \\
1-4\end{array}$ \\
\hline \#5 OKT & $\begin{array}{c}1.86(1.09)^{1} \\
1-4\end{array}$ & $\begin{array}{c}2.63(1.33)^{1} \\
1-4\end{array}$ & $\begin{array}{c}2.19(1.25) \\
1-4\end{array}$ \\
\hline \#6 OKT & $\begin{array}{c}2.91(0.45) \\
0-6\end{array}$ & $\begin{array}{c}3.19(0.79) \\
0-6\end{array}$ & $\begin{array}{c}3.03(0.63) \\
0-6\end{array}$ \\
\hline Total OKT & $3.69(1.28)^{1}$ & $2.82(1.88)^{1}$ & $3.31(1.62)$ \\
\hline
\end{tabular}


Table 3

Summation of Osteoporosis Health Belief-Benefits of and Barriers to Exercise Scale (OHBS)

\begin{tabular}{|c|c|c|c|}
\hline & $\begin{array}{c}\text { Attended } \\
\text { Fair } \\
(\mathbf{n}=35)\end{array}$ & $\begin{array}{c}\text { Did not } \\
\text { Attend Fair } \\
(\mathbf{n}=27)\end{array}$ & $\begin{array}{c}\text { Total } \\
\text { Participants } \\
(\mathrm{N}=62)\end{array}$ \\
\hline OHBS & Range & Range & Range \\
\hline \multirow[t]{2}{*}{ Benefits } & Mean (SD) & Mean (SD) & Mean (SD) \\
\hline & $3-5$ & $3-5$ & $3-5$ \\
\hline \multirow[t]{2}{*}{$\# 1$ benefits } & $4.43(0.66)$ & $4.30(0.67)$ & $4.37(0.66)$ \\
\hline & $2-5$ & $2-5$ & $2-5$ \\
\hline \multirow[t]{2}{*}{ \#2 benefits } & $4.09(0.92)$ & $3.56(1.19)$ & $3.85(1.07)$ \\
\hline & 4-5 & $3-5$ & $3-5$ \\
\hline \multirow[t]{2}{*}{ \#3 benefits } & $4.63(0.49)^{1}$ & $4.30(0.61)^{1}$ & $4.48(0.57)$ \\
\hline & $3-5$ & $3-5$ & $3-5$ \\
\hline \multirow[t]{2}{*}{ \#4 benefits } & $3.89(0.80)$ & $3.85(0.72)$ & $3.87(0.76)$ \\
\hline & $3-5$ & 3-5 & $3-5$ \\
\hline \multirow[t]{2}{*}{ \#5 benefits } & $4.37(0.55)$ & $4.26(0.71)$ & $4.32(0.62)$ \\
\hline & $2-5$ & $3-5$ & $2-5$ \\
\hline \multirow[t]{2}{*}{ \#6 benefits } & $4.29(0.83)$ & $3.96(0.81)$ & $4.15(0.83)$ \\
\hline & $22-30$ & $19-30$ & $19-30$ \\
\hline Total benefits & $25.69(2.36)^{1}$ & $24.22(2.94)^{1}$ & $25.05(2.71)$ \\
\hline \multicolumn{4}{|l|}{ OHBS } \\
\hline & $1-5$ & $1-5$ & $1-5$ \\
\hline \multirow[t]{2}{*}{ \#1 barriers } & $2.54(1.27)$ & $2.85(1.41)$ & $2.68(1.33)$ \\
\hline & $1-4$ & $1-4$ & $1-4$ \\
\hline \multirow[t]{2}{*}{ \#2 barriers } & $2.06(1.00)$ & $2.44(1.05)$ & $2.23(1.03)$ \\
\hline & $1-4$ & $1-3$ & $1-4$ \\
\hline \multirow[t]{2}{*}{ \#3 barriers } & $1.63(0.69)$ & $1.70(0.72)$ & $1.60(0.00)$ \\
\hline & $1-5$ & $1-5$ & $1-5$ \\
\hline \multirow[t]{2}{*}{ \#4 barriers } & $3.03(1.18)$ & $3.26(1.20)$ & $3.13(1.18)$ \\
\hline & $1-5$ & $1-5$ & $1-5$ \\
\hline \multirow[t]{2}{*}{ \#5 barriers } & $3.26(1.29)$ & $3.30(1.30)$ & $3.27(1.28)$ \\
\hline & $1-5$ & $1-5$ & $1-5$ \\
\hline \multirow[t]{2}{*}{ \#6 barriers } & $3.29(1.15)$ & $3.74(1.02)$ & $3.48(1.11)$ \\
\hline & $8-23$ & 6-24 & $6-24$ \\
\hline Total barriers & $15.80(3.35)$ & $17.30(4.95)$ & $16.45(4.16)$ \\
\hline
\end{tabular}

Note.

${ }^{1} \mathrm{p}<0.05$ for an independent $t$-test comparing OHSB benefit scores of those who attended BE fracture FREE and those who did not 
Table 4

Summation of Osteoporosis Self-Efficacy Scale - Exercise (OSES) Scores

\begin{tabular}{lccc} 
& $\begin{array}{c}\text { Attended } \\
\text { Fair } \\
(\mathbf{n = 3 5})\end{array}$ & $\begin{array}{c}\text { Did not } \\
\text { Attend Fair } \\
(\mathbf{n = 2 7})\end{array}$ & $\begin{array}{c}\text { Total } \\
\text { Participants } \\
(\mathbf{N = 6 2})\end{array}$ \\
\hline $\begin{array}{c}\text { Range } \\
\text { Mean }(\mathbf{S D})\end{array}$ & $\begin{array}{c}\text { Range } \\
\text { Mean (SD) }\end{array}$ & $\begin{array}{c}\text { Range } \\
\text { Mean (SD) }\end{array}$ \\
\hline Total post- score & $18-30$ & N/A & N/A \\
Total pre- score & $26.00(2.81)$ & & $9-30$ \\
Post- minus Pre- score & $3.54(2.72)^{2}$ & $19.11(5.06)^{1}$ & $20.94(4.81)$ \\
\end{tabular}

\section{Paired Samples Test}

Paired Differences

95\% CI of the difference Significance

\begin{tabular}{lcllll}
\multicolumn{1}{c}{ OSES Pairs } & $\mathbf{n}$ & Mean (SD) & Lower & Upper & (2-tailed) \\
\hline \#1 Post- minus pre- & 35 & $0.60(0.70)$ & 0.36 & 0.834 & $\mathrm{p}<0.001^{2}$ \\
\#2 Post- minus pre- & 35 & $0.66(0.73)$ & 0.41 & 0.91 & $\mathrm{p}<0.001^{2}$ \\
\#3 Post-minus pre- & 35 & $0.54(0.66)$ & 0.32 & 0.77 & $\mathrm{p}<0.001^{2}$ \\
\#4 Post- minus pre- & 35 & $0.51(0.61)$ & 0.30 & 0.72 & $\mathrm{p}<0.001^{2}$ \\
\#5 Post- minus pre- & 35 & $0.66(0.73)$ & 0.41 & 0.91 & $\mathrm{p}<0.001^{2}$ \\
\#6 Post- minus pre- & 35 & $0.57(0.85)$ & 0.28 & 0.86 & $\mathrm{p}<0.001^{2}$ \\
Total post-minus pre- & 35 & $3.5(2.715)$ & 2.17 & 4.341 & $\mathrm{p}<0.001^{2}$
\end{tabular}

Note.

${ }^{1} \mathrm{p}<0.05$ for an independent $t$-test comparing pre-OSES scores of those who attended BE fracture FREE and those who did not

${ }^{2} \mathrm{p}<0.05$ for a paired, two-tailed $t$-test comparing OSES post- attending BE fracture FREE minus pre-intervention scores 


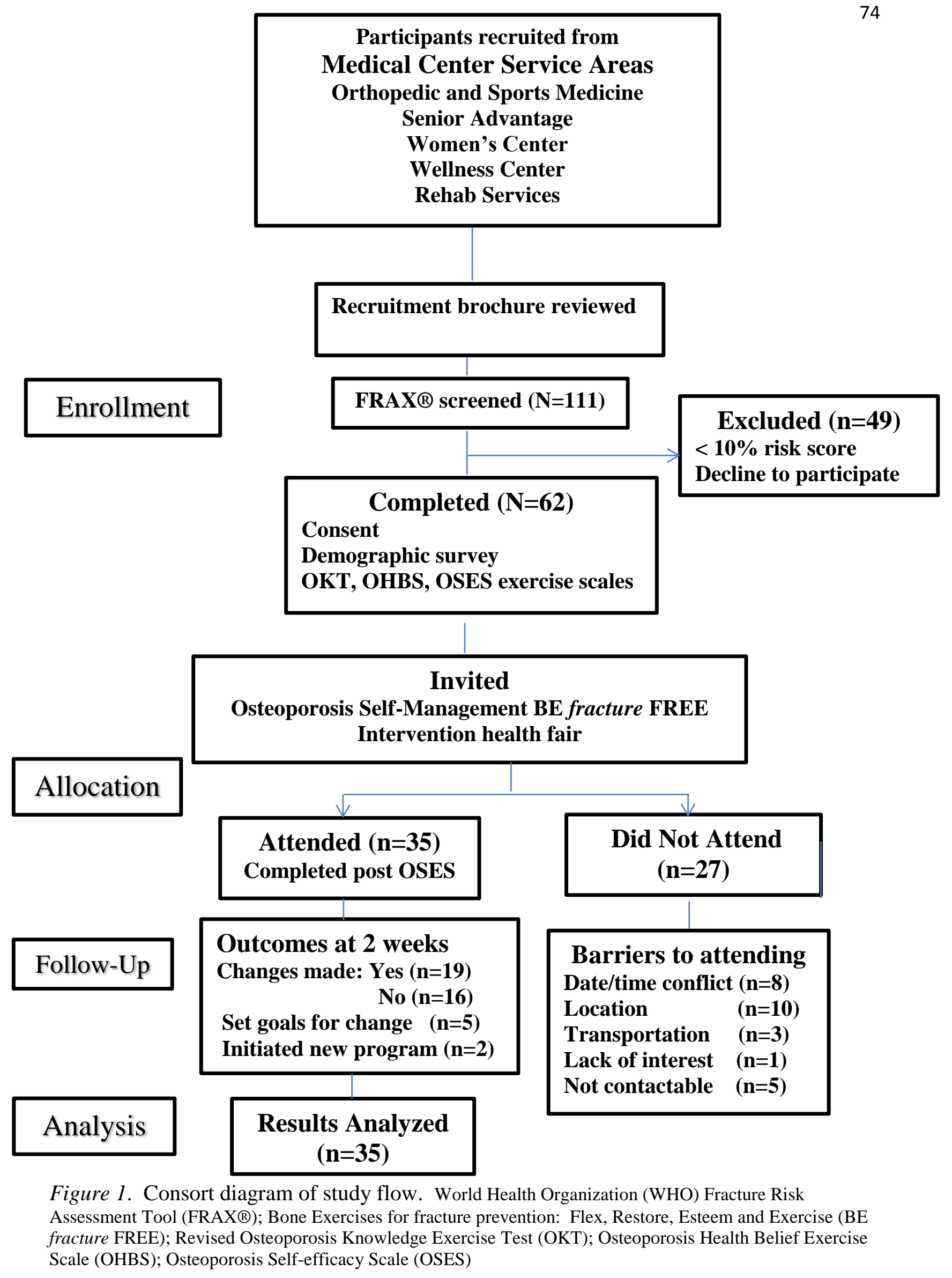




\section{References}

American College of Sports Medicine (ACSM). (2009) Guidelines for Exercise Testing and Prescription. Philadelphia, Pa: Lippincott Williams \& Wilkins.

Center for Disease Control and Preventions (CDC). (2020). Healthy People 2020, Arthritis, Osteoporosis and Chronic Back Conditions. Washington, DC. Retrieved from Centers for Disease Control and Prevention http://www.healthypeople.gov/2020/topicsobjectives2020/overview.aspx?topicid=3

Center for Disease Control and Prevention (CDC). (2011) Physical activity and health: The benefits of physical activity. Retrieved from Centers for Disease Control and Prevention:

http://www.cdc.gov/physicalactivity/everyone/health/index.html\#StrengthenBonesMus $\underline{\text { cle }}$

Babatunde, O. T., Himburg, S. P., Newman, F. L., Campa, A., \& Dixon, Z. (2011). Theorydriven intervention improves calcium intake, osteoporosis knowledge, and self-efficacy in community-dwelling older black adults. Journal of Nutrition Education and Behavior, 43(6), 434-440.

doi:http://dx.doi.org.proxy.its.virginia.edu/10.1016/j.jneb.2010.07.004

Casentini, C., Chiaramonti, G., Amedei, A., Cioppi, F., Falchetti, A., Masi, L., \& Brandi, M. L. (2011). The bone care nurse project. Clinical Cases in Mineral and Bone Metabolism: The Official Journal of the Italian Society of Osteoporosis, Mineral Metabolism, and Skeletal Diseases, 8(1), 63-65.

Chang, S. F., Yang, R. S., Chung, U. L., Chen, C. M., \& Cheng, M. H. (2010). Perception of risk factors and DXA T score among at-risk females of osteoporosis. Journal of Clinical Nursing, 19(13-14), 1795-1802. doi:10.1111/j.1365-2702.2009.03063.x 
Christmas, C., \& Andersen, R. A. (2000). Exercise and older patients: Guidelines for the clinician. Journal of the American Geriatrics Society, 48(3), 318-324. Retrieved from http://search.ebscohost.com.proxy.its.virginia.edu/login.aspx?direct=true $\& d b=0 f m \& A$ $\underline{\mathrm{N}=511154736 \& \text { site }=\text { ehost-live } \& \text { scope }=\text { site }}$

Ciesielczuk, N., Glibowski, P., \& Szczepanik, J. (2014). Awareness of factors affecting osteoporosis obtained from a survey on retired polish subjects. Roczniki Panstwowego Zakladu Higieny, 65(2), 147-153.

Endicott, R. D. (2013). Knowledge, health beliefs, and self-efficacy regarding osteoporosis in perimenopausal women. Journal of Osteoporosis, 853531 doi:10.1155/2013/853531

Estok, P. J., Sedlak, C. A., Doheny, M. O., \& Hall, R. (2008). Structural model for osteoporosis preventing behavior in postmenopausal women. Nursing Research, 56(3)(May/June), 148-158. doi:00006199-200705000-00002

Ford, M., Bass, M., Zhao, Y., Bai, B., \& Zhao, Y. (2011). Osteoporosis knowledge, selfefficacy, and beliefs among college students in the USA and china. Journal of Osteoporosis, (Article ID 729219) doi:doi:10.4061/2011/72921

Gaines, J. M., Narrett, M., \& Parrish, J. M. (2010). The effect of the addition of osteoporosis education to a bone health screening program for older adults. Geriatric Nursing, 31(5), 348-360. doi:http://dx.doi.org.proxy.its.virginia.edu/10.1016/j.gerinurse.2010.04.011

Gendler, P. E., Coviak, C. P., Martin, J. T., Kim, K. K., Dankers, J. K., Barclay, J. M., \& Sanchez, T. A. (2014). Revision of the osteoporosis knowledge test: Reliability and validity. Western Journal of Nursing Research, doi:0193945914537565 [pii]

Giangregoria, L., Papaioannou, A., Thabane, L., deBeer, J., Cranney, A., Dolovich, L., Adachi, J. (2008). Do patients perceive a link between a fragility fracture and osteoporosis? BMC Musculoskeletal Disorders, 9(38) doi: 10.1186/1471-2474-9-38 
Horan, M. L., Kim, K. K., Gendler, P., Froman, R. D., \& Patel, M. D. (1998). Development and evaluation of the osteoporosis self-efficacy scale. Research in Nursing \& Health, 21(5), 395-403. doi:10.1002/(SICI)1098-240X(199810)21:5<395::AIDNUR3>3.0.CO;2

Iloannidis, G., Papaioannou, A., Hopman, W. M., Akhtar-Danesh, N., Anastassiades, T., Pickard, L., Adachi, J. D. (2009). Relation between fractures and mortality: Results from the Canadian multicenter osteoporosis study. CMAJ: Canadian Medical Association Journal = Journal De l'Association Medicale Canadienne, 181(5), 265271. doi:10.1503/cmaj.081720

Johnson, S., McLeod, W., Kennedy, L., \& McLeod, K. (2008). Osteoporosis health beliefs among younger and older men and women. Health Education and Behavior, 35(5), 721-733. doi: $10.1177 / 1090198107301331$

Kim, Tae-Hee, Lee, Young-Sang, Byun, Dong Won, Jang, Seyeon, Jeon, Dong-Su, Lee, Hae-Hyeog. (2013). Evaluation of the osteoporosis health belief scale in Korean women. Journal of Bone Metabolism, 20, 25-30. doi:10.11005/jbm.2013.20.1.25

Kim, K. K., Horan, M. L. \& Gendler, P., (1991). Development and evaluation of the osteoporosis health belief scale. Research in Nursing \& Health, 14(2), 155-163. doi:10.1002/nur.4770140210

Kemmler, W., HÃberle, L., \& von Stengel, S. (2013). Effects of exercise on fracture reduction in older adults. Osteoporosis International, 24(7), 1937-1950. doi:10.1007/s00198-012-2248-7

Lee, Young-Shin., Baek, Jong-Duek., Yang, K., \& Yoon, S. (2012). Relationships between physical activity and awareness and treatment status among adults with low femoral bone density in the United States. American Journal of Health Promotion, 27(1), 2-9. 
Retrieved from: https://search-ebscohost-

com.proxy.its. virginia.edu/login. asp $x$ ?direct $=$ true $\& d b=s 3 h \& A N=79757533 \&$ site $=$ ehost $\underline{\text {-live }}$

McLeod, K. M., \& Johnson, C. S. (2011). A systematic review of osteoporosis health beliefs in adult men and women. Journal of Osteoporosis, 2011, 197454.

doi:10.4061/2011/197454

National Institutes of Health (NIH). (2014). Osteoporosis and related bone diseases national research center. Retrieved from National Institutes of Health:

http://www.niams.nih.gov/Health_Info/Bone/default.asp

National Osteoporosis Foundation (NOF). (2014). Osteoporosis Report. Washington, DC.

Retrieved from National Osteoporosis Foundation: http://nof.org/about/osteo-report

Nayak, S., Roberts, M. S., Chung-Chou H. Chang, \& Greenspan, S. (2010). Health beliefs about osteoporosis and osteoporosis screening in older women and men. Health Educ J., 69(3) doi: 10.1177/0017896910364570

Nguyen, V. H. (2014). An assessment of osteoporosis health beliefs based on the health belief model. International Journal of Health Promotion and Education, 52(2), 105115. doi:10.1080/14635240.2014.893138

Østbye, T., Yarnall, K. S. H., Krause, K. M., Pollak, K. I., Gradison, M., \& Michener, J. L. (2005). Is there time for management of patients with chronic diseases in primary care? Annals of Family Medicine, 3(3), 209-214. doi:0.1370/afm.310

Plawecki, K., \& Chapman-Novakofski, K. (2013). Effectiveness of community intervention in improving bone health behaviors in older adults. Journal of Nutrition in Gerontology \& Geriatrics, 32(2), 145-160. doi:10.1080/21551197.2013.781421 
Qi, B., Resnick, B., Smeltzer, S., \& Bausell, B. (2011). Self-efficacy program to prevent osteoporosis among Chinese immigrants. Nursing Research, 60(6), 393-404. doi:10.1097/NNR.0b013e3182337dc3

Rosenstock, I. M., Strecher, V. J., \& Becker, M. H. (1988). Social learning theory and the health belief model. Health Education Quarterly, 15(2), 175-183.

Sadat-Ali, M., \& Al-Turki, H. A. (2012). Genetic influence of candidate osteoporosis genes in Saudi Arabian population: A pilot study. Journal of Osteoporosis, 2012, 569145. doi:10.1155/2012/569145

Shakil, A., Gimpel, N., Rizvi, H., Diddiqui, A., Ohagi, E., Billmeir, T., \& Foster, B. (2010). Awareness of prevention of osteoporosis among south Asian women. Journal Community Health, 35, 392-397. doi:10.1007/s10900-010-9263-4

Snelling, A., Crespo, C., Schaeffer, M., Smith, S., \& Walbourn, L. (2001). Modifiable and non-modifiable factors associated with osteoporosis in postmenopausal women: results from the third national health and nutrition examination survey, 1988-1994. Journal of Women's Health \& Gender-Based Medicine, 10(1), 57-65. doi:10.1089/152460901750076124

Strength training among adults aged greater than/equal to 65 years -- United States, 2001. (2004). MMWR: Morbidity \& Mortality Weekly Report, 53(2), 25-28. Retrieved from http://search.ebscohost.com.proxy.its.virginia.edu/login.aspx?direct $=\operatorname{true} \& d b=\operatorname{cin} 20 \& A$ $\underline{\mathrm{N}=2004053450 \& \text { site }=\text { ehost-live\&scope }=\text { site }}$

Stretcher, V., \& Rosenstock, I. (1997). The health belief model. In K. Glanz, F.Lewis, \& B. Rimer, Health behavior and health education: Theory, research, and practice $\left(2^{\text {nd }}\right.$ ed., pp. 41-59). San Francisco: Jossey-Bass 
Swaim, R. A., Barner, J. C., \& Brown, C. M. (2008). The relationship of calcium intake and exercise to osteoporosis health beliefs in postmenopausal women. Research in Social and Administrative Pharmacy, 4(2), 153-163. doi:

http://dx.doi.org.proxy.its.virginia.edu/10.1016/j.sapharm.2007.03.004

Tan, S., Ji, J., Tsai, J., Eng, L., Ko, H., Yau, A., Edwards, B. (2009). Greater osteoporosis educational outreach is desirable among Chinese immigrants in Chinatown, Chicago. Osteoporosis International, 20, 1517-1522.

Turner, L. W., Hunt, S. B., DiBrezzo, R., \& Jones, C. (2004). Design and implementation of an osteoporosis prevention program using the health belief model. American Journal of Health Studies, 19(2) doi: 1090-0500

Werner, P. (2005). Knowledge about osteoporosis: assessment, correlates and outcomes. International Osteoporosis Foundation and National Osteoporosis Foundation 2004, Volume 16(Issue 2), 115-127.

World Health Organization (WHO). (2008). Fracture Risk Assessment Tool (FRAX®). ( World Health Organization Collaborating Centre for Metabolic Bone Diseases, University of Sheffield, UK, http://shef.ac.uk/FRAX/tool.aspx?country=9

World Health Organization (WHO). (2004). Scientific Group on the Assessment of Osteoporosis at Primary Health Care Level. Brussels, Belgium. Retrieved from World Health Organization: http://www.who.int/chp/topics/Osteoporosis.pdf 
Table 1

Summary of demographic and FRAX® risk characteristics

\begin{tabular}{|c|c|c|c|}
\hline & $\begin{array}{c}\text { Attended } \\
\text { Fair } \\
(\mathbf{n}=35) \\
\end{array}$ & $\begin{array}{c}\text { Did not } \\
\text { Attend Fair } \\
(n=27) \\
\end{array}$ & $\begin{array}{r}\text { Total } \\
\text { Particip } \\
(\mathrm{N}=62 \\
\end{array}$ \\
\hline Characteristics & $\begin{array}{c}\text { Range } \\
\text { Mean (SD) }\end{array}$ & $\begin{array}{c}\text { Range } \\
\text { Mean (SD) } \\
\end{array}$ & $\begin{array}{r}\text { Range } \\
\text { Mean (S) } \\
\end{array}$ \\
\hline \multicolumn{4}{|l|}{ Objective Measures } \\
\hline Frax $®$ Score & $\begin{array}{c}10-45 \\
18.83(7.90)\end{array}$ & $\begin{array}{l}10-40 \\
16.96(7.39)\end{array}$ & $\begin{array}{l}10-45 \\
18.02\end{array}$ \\
\hline Age & $\begin{array}{c}55-87 \\
66.11(6.00)\end{array}$ & $\begin{array}{l}50-86 \\
68.15(8.86)\end{array}$ & $\begin{array}{l}50-87 \\
67.00\end{array}$ \\
\hline Menopause Age & $\begin{array}{c}32-56 \\
51.54(4.44)\end{array}$ & $\begin{array}{l}48-56 \\
53.11(1.97)\end{array}$ & $\begin{array}{l}32-56 \\
52.23\end{array}$ \\
\hline Weight (lbs.) & $\begin{array}{c}100-228 \\
147.17(27.13)^{2}\end{array}$ & $\begin{array}{l}92-239 \\
158.89(40.89)^{2}\end{array}$ & $\begin{array}{r}92-23 C \\
152.27\end{array}$ \\
\hline \multirow[t]{2}{*}{ Height (cm) } & $\begin{array}{c}60-69 \\
64.66(2.43) \\
\end{array}$ & $\begin{array}{l}61-68 \\
64.24(2.00) \\
\end{array}$ & $\begin{array}{l}60-69 \\
64.48 \\
\end{array}$ \\
\hline & $\mathrm{n}(\%)$ & $\mathrm{n}(\%)$ & $\mathbf{N}(\%$ \\
\hline \multicolumn{4}{|l|}{ Non-modifiable Factors } \\
\hline $\begin{array}{l}\text { *Female } \\
\text { Male }\end{array}$ & $35(100)$ & $27(100)$ & $\begin{array}{c}62(100) \\
0(0)\end{array}$ \\
\hline \multicolumn{4}{|l|}{ Race } \\
\hline $\begin{array}{l}\text { *Caucasian } \\
\text { African American } \\
\text { Asian } \\
\text { Hispanic }\end{array}$ & $\begin{array}{r}31(89) \\
4(11)\end{array}$ & $\begin{array}{r}24(89) \\
3(11)\end{array}$ & $\begin{array}{l}55(89) \\
7(11) \\
0(0) \\
0(0)\end{array}$ \\
\hline $\begin{array}{l}\text { Parent with Hip Fracture } \\
* \text { Yes } \\
\text { No }\end{array}$ & $\begin{array}{r}9(26) \\
26(74)\end{array}$ & $\begin{array}{r}8(30) \\
19(70)\end{array}$ & $\begin{array}{l}17(27) \\
45(73)\end{array}$ \\
\hline \multicolumn{4}{|l|}{ Concomitant Diagnosis } \\
\hline $\begin{array}{c}* \text { Yes } \\
\text { No }\end{array}$ & $\begin{array}{l}13(37) \\
22(63)\end{array}$ & $\begin{array}{l}10(37) \\
17(63)\end{array}$ & $\begin{array}{l}23(37) \\
39(63)\end{array}$ \\
\hline \multicolumn{4}{|l|}{ Rheumatoid Arthritis } \\
\hline $\begin{array}{c}* \text { Yes } \\
\text { No }\end{array}$ & $\begin{array}{r}9(26) \\
26(74)\end{array}$ & $\begin{array}{c}2(7) \\
25(93)\end{array}$ & $\begin{array}{l}11(18) \\
51(82)\end{array}$ \\
\hline \multicolumn{4}{|l|}{ Risk Behaviors } \\
\hline $\begin{array}{c}* \text { Yes } \\
\text { No }\end{array}$ & $\begin{array}{l}10(29) \\
25(71)\end{array}$ & $\begin{array}{r}7(26) \\
20(74)\end{array}$ & $\begin{array}{l}17(27) \\
45(73)\end{array}$ \\
\hline \multicolumn{4}{|l|}{ Alcohol Consumption } \\
\hline $\begin{array}{l}\text { None } \\
\text { Occasional } \\
\text { *Daily }\end{array}$ & $\begin{array}{r}20(57) \\
8(23) \\
7(26)\end{array}$ & $\begin{array}{r}12(44) \\
5(19) \\
10(37)\end{array}$ & $\begin{array}{l}32(52) \\
13(21) \\
17(27)\end{array}$ \\
\hline
\end{tabular}




\begin{tabular}{lrrr}
\multicolumn{2}{l}{ Engagement in Physical Exercise } & & \\
Yes & $8(23)$ & $6(22)$ & $14(23)$ \\
$*$ No $<3$ times a week & $12(34)$ & $7(26)$ & $19(31)$ \\
$>3$ times a week & $6(17)$ & $3(11)$ & $9(14)$ \\
$*$ None & $9(26)$ & $11(41)$ & $20(32)$ \\
\hline
\end{tabular}

Note. *Characteristics and risk behaviors increasing Frax ${ }^{\circledR}$ Score

${ }^{1} \mathrm{p}<0.05$ for an exact chi-square test comparing those who attended BE fracture FREE and those who did not (no significant results noted in categorical variables)

${ }^{2} \mathrm{p}<0.05$ for an independent $t$-test comparing those who attended BE fracture FREE and those who did not (one significant result noted in weight variable) 
Table 2

Summation of Revised Osteoporosis Knowledge Test-Exercise (OKT) Scores

\begin{tabular}{|c|c|c|c|}
\hline & $\begin{array}{c}\text { Attended } \\
\text { Fair } \\
(\mathbf{n}=35) \\
\end{array}$ & $\begin{array}{c}\text { Did not } \\
\text { Attend Fair } \\
(n=27)\end{array}$ & $\begin{array}{c}\text { Total } \\
\text { Participants } \\
(\mathrm{N}=62)\end{array}$ \\
\hline & $\begin{array}{c}\text { Range } \\
\text { Mean (SD) }\end{array}$ & $\begin{array}{c}\text { Range } \\
\text { Mean (SD) }\end{array}$ & $\begin{array}{c}\text { Range } \\
\text { Mean (SD) }\end{array}$ \\
\hline & $1-4$ & $1-4$ & $1-4$ \\
\hline \#1 OKT & $\begin{array}{c}2.60(0.88) \\
1-4\end{array}$ & $\begin{array}{c}2.41(1.08) \\
1-4\end{array}$ & $\begin{array}{c}2.52(.97) \\
1-4\end{array}$ \\
\hline \#2 OKT & $\begin{array}{c}1.97(0.71)^{1} \\
1-4\end{array}$ & $\begin{array}{c}2.41(0.97)^{1} \\
1-4\end{array}$ & $\begin{array}{c}2.16(0.85) \\
1-4\end{array}$ \\
\hline \#3 OKT & $\begin{array}{c}2.46(0.82) \\
1-4\end{array}$ & $\begin{array}{c}2.37(0.88) \\
1-4\end{array}$ & $\begin{array}{c}2.42(0.84) \\
1-4\end{array}$ \\
\hline \#4 OKT & $\begin{array}{c}2.26(1.01)^{1} \\
1-4\end{array}$ & $\begin{array}{c}3.00(1.00)^{1} \\
1-4\end{array}$ & $\begin{array}{c}2.58(1.06) \\
1-4\end{array}$ \\
\hline \#5 OKT & $\begin{array}{c}1.86(1.09)^{1} \\
1-4\end{array}$ & $\begin{array}{c}2.63(1.33)^{1} \\
1-4\end{array}$ & $\begin{array}{c}2.19(1.25) \\
1-4\end{array}$ \\
\hline \#6 OKT & $\begin{array}{c}2.91(0.45) \\
0-6\end{array}$ & $\begin{array}{c}3.19(0.79) \\
0-6\end{array}$ & $\begin{array}{c}3.03(0.63) \\
0-6\end{array}$ \\
\hline Total OKT & $3.69(1.28)^{1}$ & $2.82(1.88)^{1}$ & $3.31(1.62)$ \\
\hline
\end{tabular}


Table 3

Summation of Osteoporosis Health Belief-Benefits of and Barriers to Exercise Scale (OHBS)

\begin{tabular}{lccc} 
& $\begin{array}{c}\text { Attended } \\
\text { Fair } \\
(\mathbf{n = 3 5})\end{array}$ & $\begin{array}{c}\text { Did not } \\
\text { Attend Fair } \\
(\mathbf{n = 2 7})\end{array}$ & $\begin{array}{c}\text { Total } \\
\text { Participants } \\
(\mathbf{N = 6 2})\end{array}$ \\
\hline OHBS & Range & Range & Range \\
Benefits & Mean (SD) & Mean (SD) & Mean (SD) \\
\hline \#1 benefits & $3-5$ & $3-5$ & $3-5$ \\
& $4.43(0.66)$ & $4.30(0.67)$ & $4.37(0.66)$ \\
\#2 benefits & $2-5$ & $2-5$ & $2-5$ \\
\#3 benefits & $4.09(0.92)$ & $3.56(1.19)$ & $3.85(1.07)$ \\
& $4-5$ & $3-5$ & $3-5$ \\
\#4 benefits & $4.63(0.49)$ & $4.30(0.61)$ & $4.48(0.57)$ \\
\#5 benefits & $3-5$ & $3-5$ & $3-5$ \\
& $3.89(0.80)$ & $3.85(0.72)$ & $3.87(0.76)$ \\
\#6 benefits & $3-5$ & $3-5$ & $3-5$ \\
& $4.37(0.55)$ & $4.26(0.71)$ & $4.32(0.62)$ \\
Total benefits & $2-5$ & $3-5$ & $2-5$ \\
& $4.29(0.83)$ & $3.96(0.81)$ & $4.15(0.83)$ \\
& $22-30$ & $19-30$ & $19-30$ \\
& $25.69(2.36)$ & $24.22(2.94)$ & $25.05(2.71)$
\end{tabular}

OHBS

Barriers

\begin{tabular}{lccc}
\hline & $1-5$ & $1-5$ & $1-5$ \\
\#1 barriers & $2.54(1.27)$ & $2.85(1.41)$ & $2.68(1.33)$ \\
& $1-4$ & $1-4$ & $1-4$ \\
\#2 barriers & $2.06(1.00)$ & $2.44(1.05)$ & $2.23(1.03)$ \\
& $1-4$ & $1-3$ & $1-4$ \\
\#3 barriers & $1.63(0.69)$ & $1.70(0.72)$ & $1.60(0.00)$ \\
& $1-5$ & $1-5$ & $1-5$ \\
\#4 barriers & $3.03(1.18)$ & $3.26(1.20)$ & $3.13(1.18)$ \\
& $1-5$ & $1-5$ & $1-5$ \\
\#5 barriers & $3.26(1.29)$ & $3.30(1.30)$ & $3.27(1.28)$ \\
& $1-5$ & $1-5$ & $1-5$ \\
\#6 barriers & $3.29(1.15)$ & $3.74(1.02)$ & $3.48(1.11)$ \\
& $8-23$ & $6-24$ & $6-24$ \\
Total barriers & $15.80(3.35)$ & $17.30(4.95)$ & $16.45(4.16)$
\end{tabular}

Note.

${ }^{1} \mathrm{p}<0.05$ for an independent $t$-test comparing OHBS benefit scores of those who attended BE fracture FREE and those who did not 
Table 4

Summation of Osteoporosis Self-Efficacy Scale - Exercise (OSES) Scores

\begin{tabular}{lccc} 
& $\begin{array}{c}\text { Attended } \\
\text { Fair } \\
(\mathbf{n = 3 5})\end{array}$ & $\begin{array}{c}\text { Did not } \\
\text { Attend Fair } \\
(\mathbf{n = 2 7})\end{array}$ & $\begin{array}{c}\text { Total } \\
\text { Participants } \\
(\mathbf{N = 6 2})\end{array}$ \\
\hline $\begin{array}{c}\text { Range } \\
\text { Mean (SD) }\end{array}$ & $\begin{array}{c}\text { Range } \\
\text { Mean (SD) }\end{array}$ & $\begin{array}{c}\text { Range } \\
\text { Mean (SD) }\end{array}$ \\
\hline Total post- score & $18-30$ & N/A & N/A \\
Total pre- score & $26.00(2.81)$ & & $9-30$ \\
Post- minus Pre- score & $3.54(2.72)^{2}$ & $19.11(5.06)^{1}$ & $20.94(4.81)$ \\
\end{tabular}

Paired Samples Test

Paired Differences

95\% CI of the difference Significance

\begin{tabular}{lccccc}
\multicolumn{1}{c}{ OSES Pairs } & $\mathbf{n}$ & Mean (SD) & Lower & Upper & (2-tailed) \\
\hline \#1 Post- minus pre- & 35 & $0.60(0.70)$ & 0.36 & 0.834 & $\mathrm{p}<0.001^{2}$ \\
\#2 Post- minus pre- & 35 & $0.66(0.73)$ & 0.41 & 0.91 & $\mathrm{p}<0.001^{2}$ \\
\#3 Post-minus pre- & 35 & $0.54(0.66)$ & 0.32 & 0.77 & $\mathrm{p}<0.001^{2}$ \\
\#4 Post- minus pre- & 35 & $0.51(0.61)$ & 0.30 & 0.72 & $\mathrm{p}<0.001^{2}$ \\
\#5 Post- minus pre- & 35 & $0.66(0.73)$ & 0.41 & 0.91 & $\mathrm{p}<0.001^{2}$ \\
\#6 Post- minus pre- & 35 & $0.57(0.85)$ & 0.28 & 0.86 & $\mathrm{p}<0.001^{2}$ \\
Total post-minus pre- & 35 & $3.5(2.715)$ & 2.17 & 4.341 & $\mathrm{p}<0.001^{2}$
\end{tabular}

Note.

${ }^{1} \mathrm{p}<0.05$ for an independent $t$-test comparing pre-OSES scores of those who attended BE fracture FREE and those who did not

${ }^{2} \mathrm{p}<0.05$ for a paired, two-tailed $t$-test comparing OSES post- attending BE fracture FREE minus pre-intervention scores 


\section{Health Belief Model}

\begin{tabular}{|l|}
\hline Individual \\
Perceptions
\end{tabular}

$$
\text { Modifying Factors }
$$

Likelihood

of action

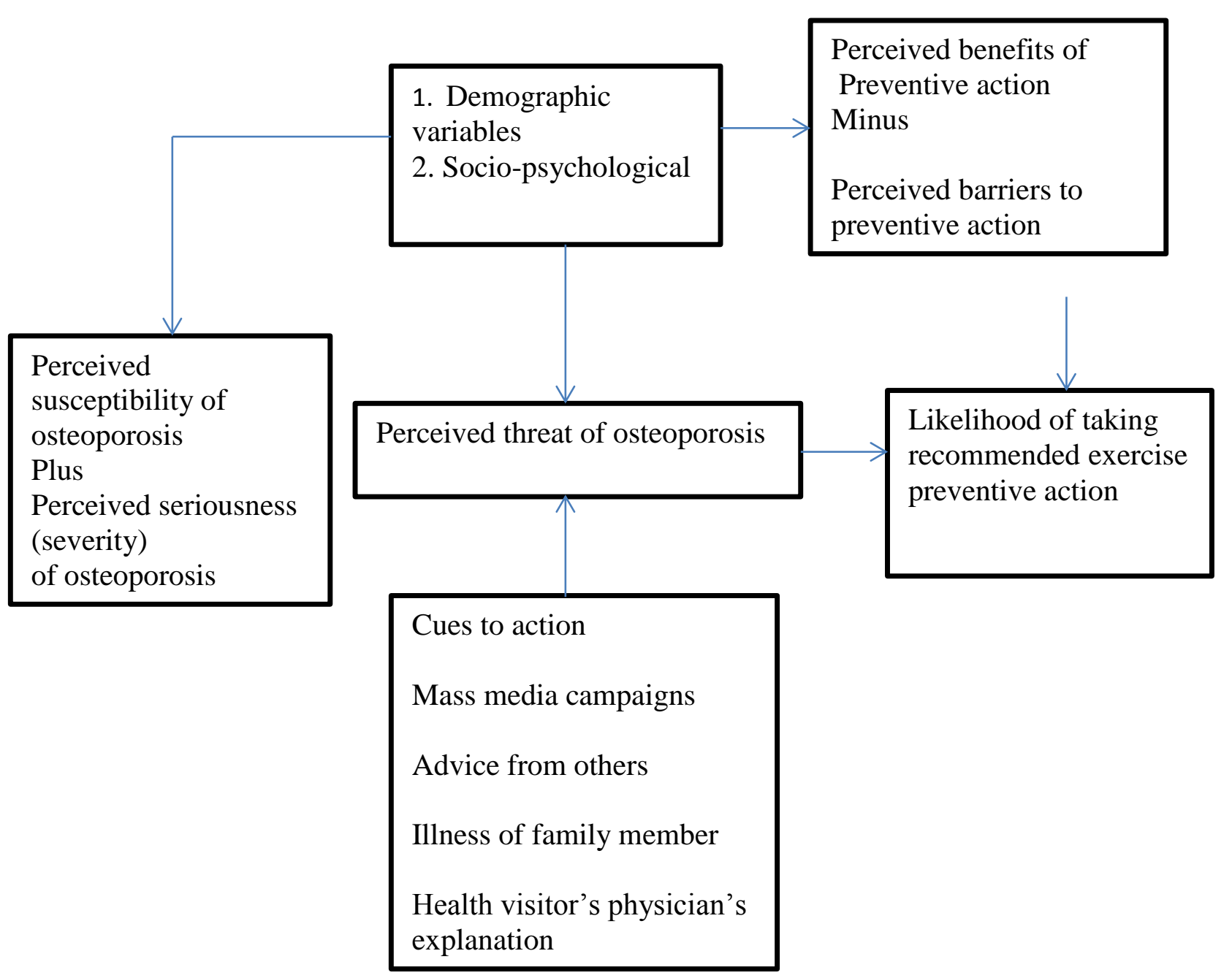

Figure 1. Revised Health Belief Model (Stretcher \& Rosenstock, 1997) 


\section{Health Belief Model (HBM) Variables}

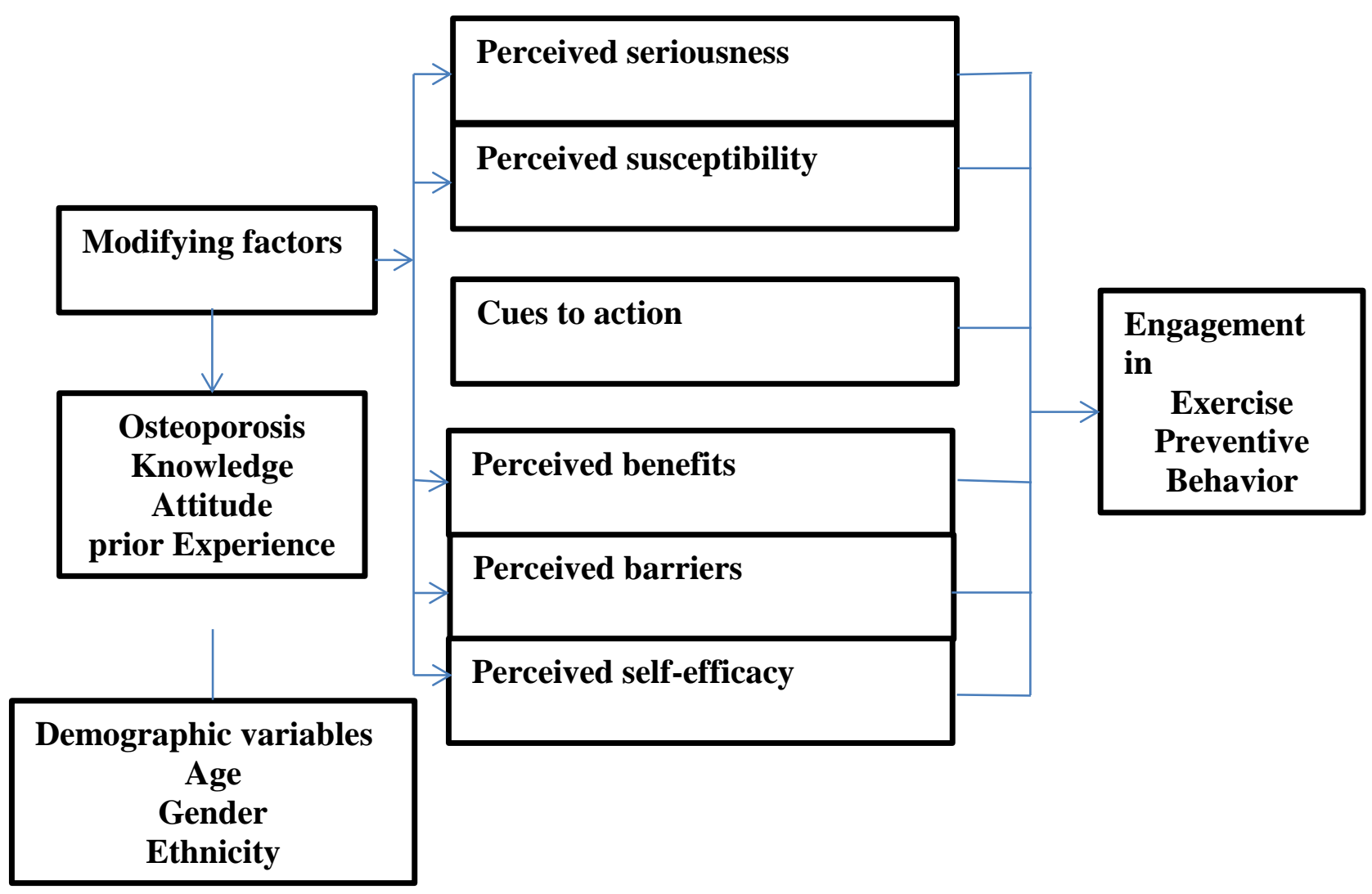

Figure 2. Health Belief Model (HBM) with variables examined in this study 
BE fracture FREE

Related intervention strategies

Components of Revised Health Belief Model (Description of activities)

Perceived Seriousness Educational components included a review of materials from the National Osteoporosis Foundation (NOF) relevant to effective exercise intervention, presented with focused discussion regarding osteoporosis exercise prevention behaviors, perceived susceptibility, susceptibility of developing osteoporosis and recommended health measures were discussed

Perceived Benefits (Exercise) Focus on the benefits to exercise

Perceived Barriers (Exercise) Strategies to minimize barriers to exercise highlighted

Modifying Variables Personal health history and risk factors identified

Cues to Action

FRAX® Calculator scores

Self-efficacy

Verbal persuasion Expert physical activity speakers discussed exercise options assessable in the community, Silver Sneakers program

Role Models $\quad$ Exhibitors and speakers demonstrated and performed specific activities including: Walking, mountain biking, running, hiking, Pilates, Golden Zumba, Nia, Progressive Exercise (ProEX), resistance training, aerobic dance, Tai Chi

Performance

Accomplishment

Coaches encouraged sharing with others their successful exercise enhanced lifestyle experiences Small individual goals set with the participants for exercise that can be consecutively mastered so they may experience success. Individual goals and guidance provided based on individual risk factors, prior exercise experience and built on weight bearing, resistance training or balance and flexibility enhancing exercise.

Variable Measures

Post-intervention Exercise Osteoporosis Self-Efficacy Scale (OSES)

Follow up

Study investigator contacted individuals within 2 weeks to collect intervention outcome data: any change in regular weight bearing or resistive training exercise; new program goal or initiation of post-intervention exercise plan.

Figure 3. Osteoporosis self-management exercise promotion health fair intervention BE: Bone Exercises, FREE: Flex, Restore, Esteem and Exercise (BE fracture FREE) Fracture Risk Assessment Tool (FRAX®) 


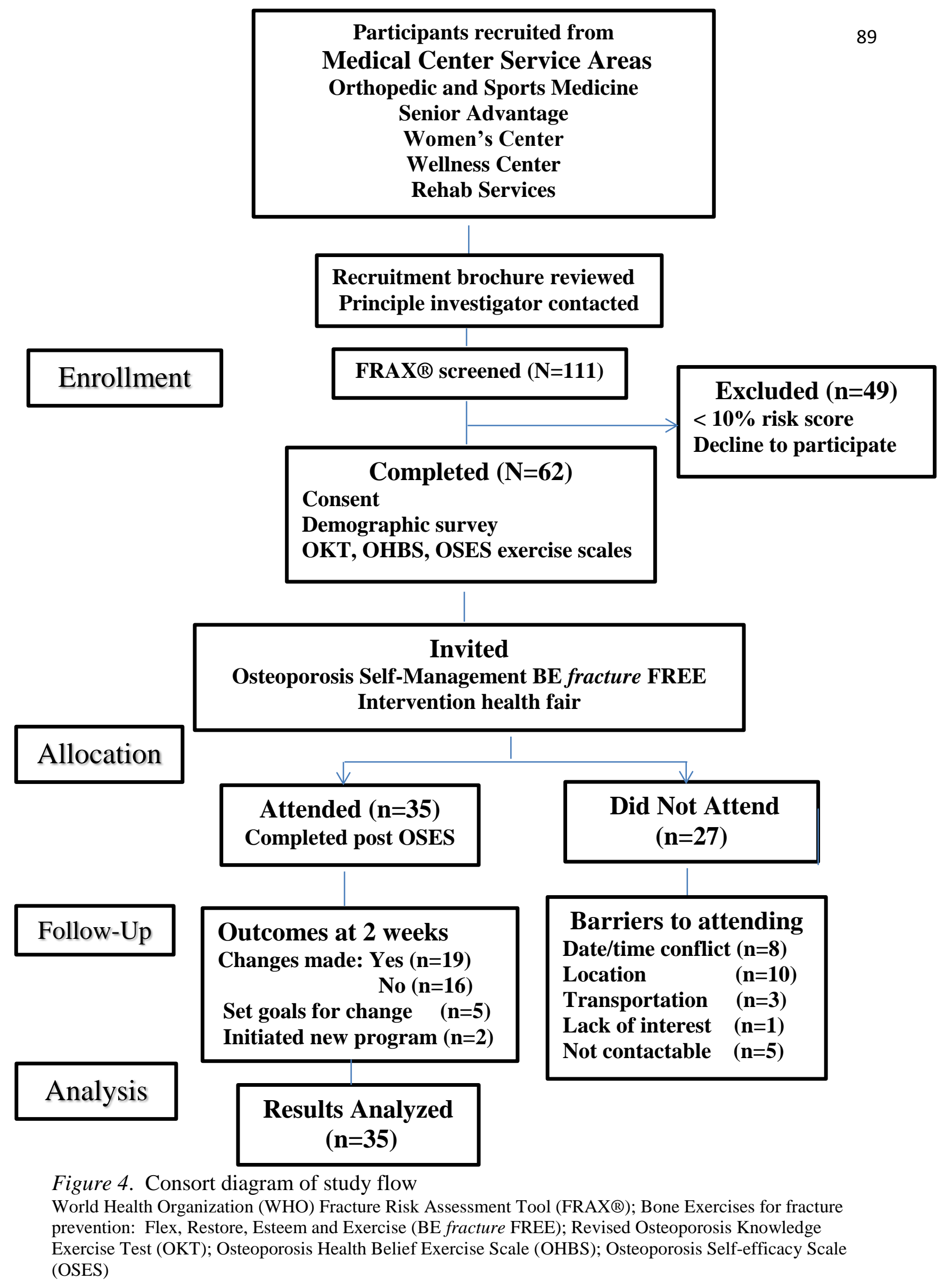




\begin{tabular}{|c|c|c|c|}
\hline Variables & Measurements/Questionnaires & $\begin{array}{l}\text { Number of items, score range, } \\
\text { and interpretation }\end{array}$ & Reliability \\
\hline $\begin{array}{l}\text { Objective demographic data } \\
\text { age, gender, ethnicity } \\
\text { post-menopausal age } \\
\text { weight, height }\end{array}$ & $\begin{array}{l}\text { Socio-demographic survey, } \\
\text { self-report of descriptive } \\
\text { non-modifiable information } \\
\text { age at menopause, fracture history }\end{array}$ & $\begin{array}{l}17 \text { demographic items } \\
\text { variable information }\end{array}$ & self-reported \\
\hline \multicolumn{4}{|l|}{ Participants' characteristics } \\
\hline $\begin{array}{l}\text { Health information } \\
\text { and osteoporosis } \\
\text { preventive behaviors }\end{array}$ & $\begin{array}{l}\text { Modifiable risk factors: exercise history } \\
\text { (regularity, type, duration, intensity) } \\
\text { history of bone mineral density (BMD) } \\
\text { tests and results, smoking and alcohol } \\
\text { habits, self-perceived health status. }\end{array}$ & & \\
\hline Osteoporosis risks & $\begin{array}{l}\text { FRAX® screening (World } \\
\text { Health Organization } \\
(\text { WHO, 2008) }\end{array}$ & $\begin{array}{l}\text { Internet } 10 \text { year risk of fracture } \\
\text { calculator, } \geq 3 \% \text { hip, } \geq 20 \% \text { for } \\
\text { major osteoporotic fracture is } \\
\text { significant predictor of future } \\
\text { fracture risk. }\end{array}$ & $\begin{array}{l}\text { Only model based on } \\
\text { multiple languages, } \\
\text { and extensive data } \\
\text { from multiple cohorts }\end{array}$ \\
\hline Osteoporosis knowledge & $\begin{array}{l}\text { Revised Osteoporosis Knowledge } \\
\text { Exercise Test (OKT); (Gendler, } \\
\text { Coviak, Martin \& Kim, 2011) is } \\
\text { used to measure knowledge of } \\
\text { osteoporosis, particularly the } \\
\text { preventive strategies related to } \\
\text { exercise. }\end{array}$ & $\begin{array}{l}6 \text { item exercise subscale, } \\
\text { score } 0 \text { to } 6(100 \%) \text {, with } \\
\text { higher scores indicating } \\
\text { greater osteoporosis } \\
\text { exercise knowledge. }\end{array}$ & $\begin{array}{l}\text { Cronbach's alpha of } \\
\text { the revised OKT } \\
\text { subscale was .81 } \\
\text { (Gendler et al., 2014) }\end{array}$ \\
\hline Osteoporosis & Osteoporosis Health Belief Exercise & 12 items with exercise & Cronbach's alpha of \\
\hline Health beliefs & $\begin{array}{l}\text { Scale (OHBS), (Kim, Horan, \& } \\
\text { Gendler, 1991) is used to measure } \\
\text { beliefs related to exercise benefits } \\
\text { and barriers to osteoporosis exercise } \\
\text { prevention behavior. }\end{array}$ & $\begin{array}{l}\text { subscales score } 6 \text { to } 30 \text { each } \\
(100 \%) \text {, with higher scores } \\
\text { indicating greater perception } \\
\text { of osteoporosis health beliefs. }\end{array}$ & $\begin{array}{l}\text { OHBS exercise scale } \\
\text { Barriers .82 } \\
\text { Benefits } .81 \\
\text { (Gendler et al., 2014) }\end{array}$ \\
\hline
\end{tabular}


Self-efficacy

Failed participation

in intervention

BE fracture

FREE at 2 weeks

post-intervention

Bone health behaviors

at 2 weeks

post-intervention
Osteoporosis Self-efficacy Scale (OSES)

(Horan et al., 1998) is

used to measure self-efficacy, or

confidence in performing osteoporosis

exercise prevention behaviors.
6 item exercise subscale, score 6 to $30(100 \%)$, with higher scores implying the participant believes in their ability to succeed with exercise behaviors.
Cronbach's alpha of the OSES exercise scale was .90

(Gendler et al., 2014)

Principle investigator will contact subject who was invited but failed to participate to ask: "We missed you at the exercise health fair. Would you be willing to tell me your reasons (barriers) for why you did not attend the health fair?

Principle investigator will contact health fair participant and ask: "Have you made any change in your weight bearing or resistive training exercise since the fair? If yes what? If no, have you made any new program goals or initiated a new exercise plan?"

Figure 5. Description of study variables, measures and reliability/validity

World Health Organization (WHO) Fracture Risk Assessment Tool (FRAX®); BE: Bone Exercises, FREE: Flex, Restore, Esteem and Exercise (BE fracture FREE); Osteoporosis Health Belief Exercise Scale (OSBS), Osteoporosis Knowledge Exercise Test (OKT);

Osteoporosis Self-efficacy Exercise Scale (OSES) 


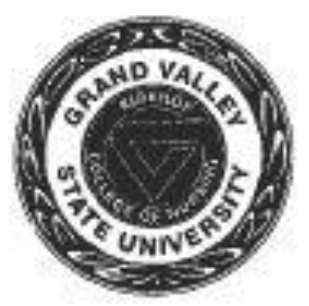

April 20, 2015

Hilda Taylor MSN, RN, CNS

Doctor of Nursing Practice Student

Instructor of Nursing

James Madison University

800 S. Main Street

Harrisonburg, Virginia 22807

Dear Ms. Taylor,

Thank you for your interest in the Osteoporosis Health Belief Scale (OHBS), Revised Osteoporosis Knowledge Test (ROKT, 2011, 2012), Osteoporosis Self-Efficacy Scale21 (OSES-21) and Osteoporosis Self-Efficacy Scale-12 (OSES-12). You have my permission to use the instruments. Please keep us informed of any publications and/or presentations and send us an abstract or summarize your study results when completed.

I wish you much success with your study.

Sincerely,

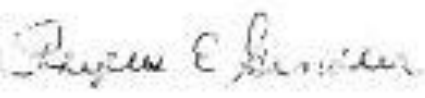

Phyllis Gendler, PhD, RN

Professor Emerita of Nursing

Cook-DeVos Center for Health Science

Kirkhof College of Nursing

Grand Valley State University

301 Michigan St. NE

Grand Rapids, MI 49503

Phone: 616-331-7161

Fax: 616-331-7362

E-mail: gendlerp@gvsu.edu

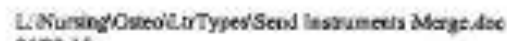

0430.15

Figure 6. Permission to use OKT revised (2012), OHBS, OSES instruments 
Appendix A

Study Participant Recruitment Brochure

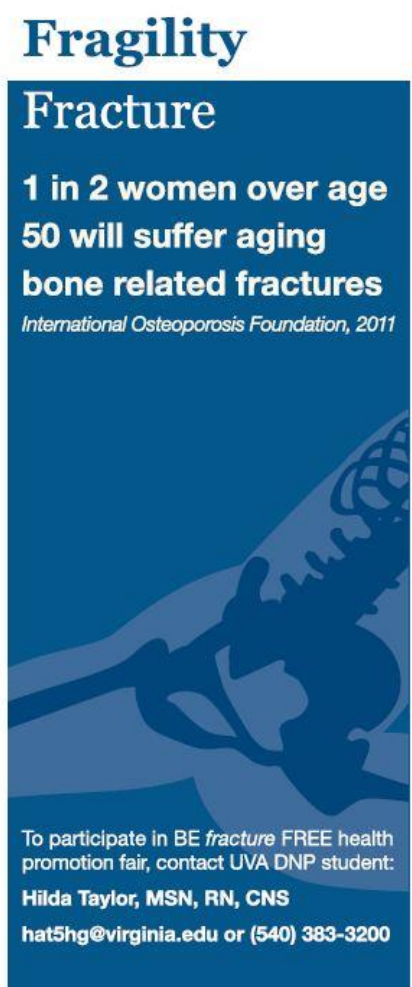

Contact

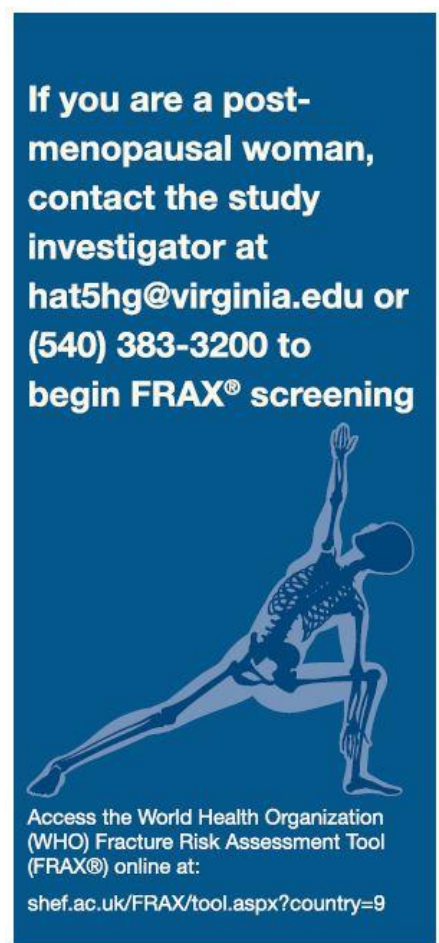

B.E.

F.R.E.E.
for fragility
fracture prevention

\section{Bone}

Exercises

Flex your muscles

Restore your bones

Esteem active lifestyle

Exercise to reduce risk

There are no monetary benefits or foreseeable risks or discomforts to the participant.

Informed participant signed consent is required to be included in the research study.

Participant confidentiality will be maintained.

\section{Register}

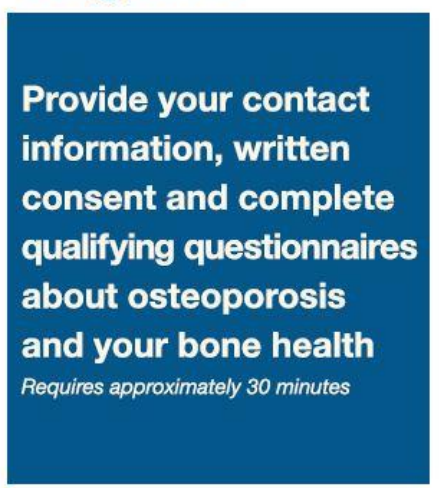

\section{Exercise Demonstrations}

Zumba Gold Aerobic Dance SilverSneakers Pilates Physical Therapy Walking Resistive training Running ProEx-osteoporosis Hiking Mountain Biking Tai Chi

\section{Osteoporosis}

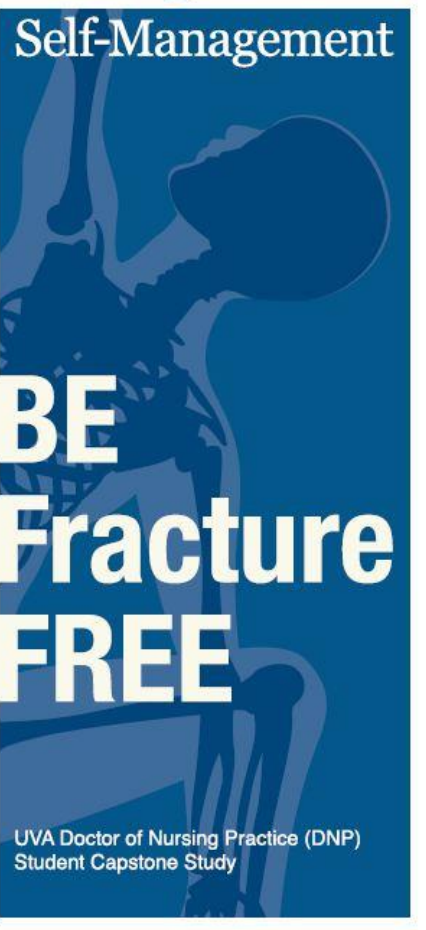

\section{Participate}

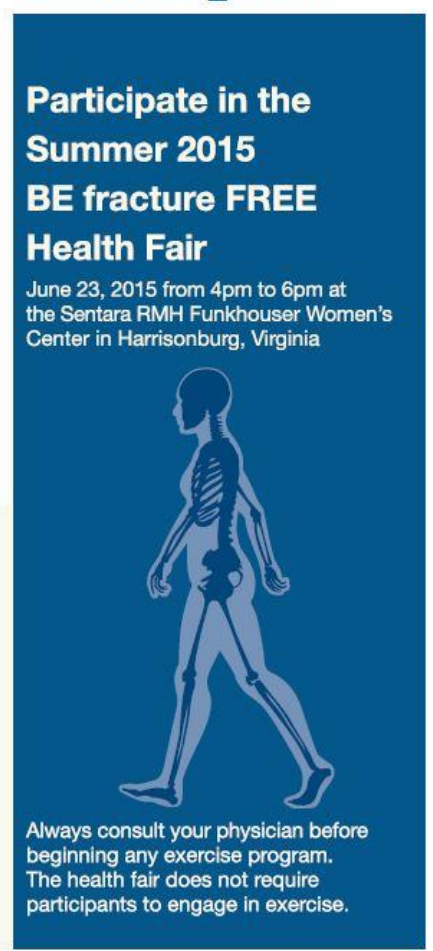




\section{Appendix B}

\section{Study Introduction}

Participant and Principle Investigator Script

Thank you for asking (calling) to find out more about our research study or I am returning your call to provide more information about our research study.

My name is Hilda Taylor, and I am a Doctor of Nursing Practice student at the University of Virginia. The purpose of our research study, Exercise for Osteoporosis Prevention, is to look at the relationship between a postmenopausal women's fracture risk and their confidence to engage in exercise. Specifically we want to determine whether women who are at higher risk for aging bone fractures will improve their exercise confidence after attending an exercise health promotion fair, BE fracture FREE.

We will be asking women to complete a fracture risk assessment using an anonymous web based FRAX® calculator. This tool has been developed by the World Health Organization to evaluate fracture risk of patients. It is based on individual patients and incorporates the fracture probability associated with clinical risk factors.

The FRAX ${ }^{\circledR}$ calculator gives the 10 -year probability of suffering a fracture. The output is a 10 -year probability of hip fracture and the 10-year probability of a major aging bone fracture (clinical spine, forearm, hip or shoulder fracture). To be considered for our study, participants need to have a fracture risk as high as $10 \%$ or more. If people meet this initial screening requirement they will be asked to complete a questionnaire requiring less than 30 minutes of their time. After completing the questionnaire participants will be invited to attend a two hour exercise health promotion fair to be held at the Sentara Funkhauser Women's Center in Harrisonburg, VA. This event will showcase a variety of fracture risk reducing exercise demonstrations and venues available in the Harrisonburg area.

There is no known risk or discomforts associated with this study. Those attending may benefit from this event, by improving their confidence to engage in exercise beneficial to bone health. National Osteoporosis Foundation educational pamphlets will be given to participants. Additionally, there is no payment for participation in any portion of this study.

Do you have any questions or concern? Now that you have a basic understanding of the study, do you think you might be interested in participating?

If No: Thank you very much for asking (calling). (End call)

\section{Caller is Interested}

But before enrolling people in this study, we need to determine if you may be eligible to participate. I would now like to ask you a series of questions about your bone health risk factors. It will take approximately 10 minutes of your time.

There is a possibility that some of these questions may make you uncomfortable or distressed; if so, please let me know. You can skip questions you do not wish to answer. 
I will keep all the information I receive from you by phone, including your initials and any other contact information confidential.

The purpose of these questions is to determine whether you may be eligible to participate in the study. Remember, your participation is voluntary; you do not have to complete these questions. Please feel free to stop me at any time if you have any questions or concerns.

Do I have your permission to ask you these questions?

\section{Post Response Communication}

\section{Potentially eligible for the study}

Based on your answers to the FRAX® calculator, it appears you may be eligible to participate in the research study.

Would you like to schedule a time to meet with me to obtain more details about the study, or to complete the next step, the questionnaire? You may choose to complete the questionnaire on line, or if you would like me to I can send you a printed copy in the mail or meet with you in person.

Obtain the potential subject's contact information.

Any report of this research that is made available to the public will not include names or any other individual information by which a participant may be identified.

\section{Not eligible for the study}

Unfortunately based on your responses you are not eligible to participate in the research study but you are welcome to attend the BE fracture FREE exercise promotion fair if you wish. 


\section{Appendix C}

Consent to participate in "Non-medical Research"

Study Title

Exercise for Osteoporosis Prevention: A Health Belief Model Guided Intervention

Principle Investigator

Hilda Taylor, MSN, RN CNS

Doctor of Nursing Practice candidate

University of Virginia School of Nursing

\section{This is a consent form for research participation}

It contains important information about this study and what to expect if you decide to participate. Please consider the information carefully. Feel free to discuss the study with your friends and family and to ask questions before making decisions whether or not to participate.

\section{Why is this study being done?}

The proposed study goal is to promote osteoporosis exercise prevention behaviors among post-menopausal women at higher risk for fractures. Sufficient osteoporosis knowledge along with attitudes, beliefs and confidence for bone health exercise prevention behaviors are important factors in the management of osteoporosis.

\section{How many people will take part in this study?}

A minimum of 30 post-menopausal women are anticipated to participate in the study.

\section{How long will I be in the study?}

30 minutes to answer the initial questionnaires. Additional participation in a two hour exercise health promotion fair is requested to complete the study.

4. What risks, side effects or discomforts can I expect from being in the study? The interventions during this study pose no foreseeable risk or discomforts for the

participant.

\section{What benefits can I expect from being in the study?}

The main benefit of this study is that the participants will learn about osteoporosis, the risk factors, and preventive exercise measures. This may improve their self-confidence to exercise thereby improving their quality of life. Furthermore, the results of the planned study may help health care providers who wish to develop osteoporosis intervention programs targeting women with higher risk for fractures.

\section{Will my study-related information be kept confidential?}

The information provided in this study will be confidential and treated as such. All participant information will only be available to the principle investigator who will maintain all information in a secure manner.

7. What are my rights if I take part in this study?

If you choose to participate in the study, you may discontinue participation at any time without penalty or loss of benefits. By signing this form, you do not give up any personal legal rights you may have as a participant in this study. 


\section{Who can answer my questions about the study?}

For questions, concerns, or complaints about the study you may contact: The principle investigator; Hilda Taylor MSN, RN, CNS. Contact (540) 5688850 or email her at hat5hg@uva.edu.

For questions about your rights as a participant in this study or to discuss other concerns or complaints with someone who is not part of the research team, you may contact the Sentara RMH IRB office at 540-689-2368 between the hours of 8:00-4:30 Monday-Friday or leave a voicemail message for follow-up during business hours.

\section{Signing the consent form}

I have read this form, and I am aware that I am being asked to participate in a research study. I have had the opportunity to ask questions and have had them answered to my satisfaction. I voluntarily agree to participate in this study. I am not giving up any legal rights by signing this form. I will be given a copy of this form.

Printed name of subject

Signature of subject

Date

\section{Principle Investigator}

I have explained the research to the participant before requesting the signature above. A copy of this form has been given to the participant.

Printed name of investigator

Signature of investigator

Date 


\section{Appendix D}

FRAX® WHO Fracture Risk Assessment Tool Sample (WHO, 2008)

\section{Calculation Tool $\quad$ www.shef.ac.uk/FRAX/tool.jsp}

Please answer the questions to calculate the ten year probability of fracture with

BMD.

Country: US (Caucasian) Name/ID:

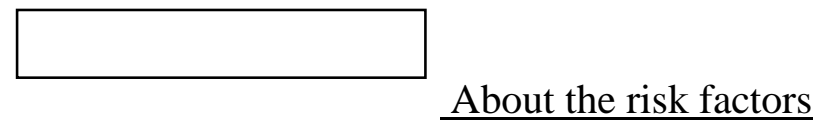

Questionnaire: 10. Secondary osteoporosis $\quad$ No $\quad$ Yes

1. Age Date of Birth 11. Alcohol 3 or more units/day oNo $\circ$ Yes

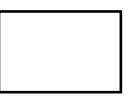

12. Femoral neck BMD $\left(\mathrm{g} / \mathrm{cm}^{2}\right)$

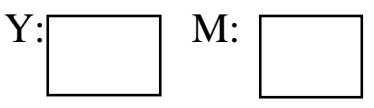

D:

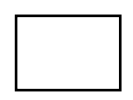

Select BMD

2. Sex $\circ$ Male $\circ$ Female

3. Weight $(\mathrm{kg})$

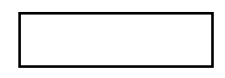

Clear

Calculate

4. Height $(\mathrm{cm})$

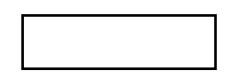

5. Previous Fracture

○No $\quad$ Yes

6. Parent Fractured Hip

○No $\quad$ Yes

7. Current Smoking

○No $\quad$ Yes

8. Rheumatoid arthritis

○No oYes

BMI:

The ten year probability of fracture (\%)

With or without BMD

Major osteoporotic \%

Hip Fracture \% 


\section{Appendix E}

Demographic Survey

Please answer all the questions: Initials

Participant number

1. Contact \#1 Phone:

2. Contact \#2 Email:

3. Age:

4. Are you a Female?

5. What ethnicity are you? Caucasian ___ African American___Asian___Hispanic

6. Years of age at menopause (12 months post menstrual period):

7. Do you engage in physical activity 3 times a week? Yes No (Indicate frequency)

8. What physical activity do you engage in?

9. Have you suffered an osteoporotic fracture (fragility fracture)? Yes No if yes where/when

10. Parent history of hip fractures: Yes No

11. Weight Height Change in Height (loss)

12. Do you smoke? Yes No

13. Alcohol consumption: none occasional daily

14. Self-rated health status: Poor Fair Good Excellent

15. Do you have Rheumatoid arthritis?

Yes No

16. FRAX®score:

17. Bone Mineral Density (T score) 


\section{Appendix F}

Osteoporosis Knowledge Test (OKT) revised (2012) Exercise Subscale

For the next group of questions, circle one answer from the four choices. Be sure to (circle) only one answer. If you think there is more than one answer, choose the best answer. If you are not sure choose D. Don't know. Circle one answer

1. To strengthen bones, it is recommended that a person exercise at a moderately intense level for 30 minutes a day at
A. 3 days a week
D. Don't know
B. 4 days a week
C. 5 days a week

2. Exercise makes bones strong, but it must be strenuous enough to make breathing:
A. Just a little faster
D. Don't know
B. So fast that talking is possible
C. So fast that talking is not possible

3. Which of the following exercises is the best way to reduce a person's chance of getting osteoporosis?
A. Swimming
D. Don't know
B. Walking briskly
C. Stretching

4. Which of the following exercises is the best way to reduce a person's chances of getting osteoporosis?
A. Bicycling
D. Don't know
B. Yoga
C. Lifting weights

5. Which of the following exercises is the best way to reduce a person's chances of getting osteoporosis?
A. Jogging or running
D. Don't know
B. Golfing using golf cart
C. Gardening

6. Which of the following exercises is the best way to reduce a person's chances of getting osteoporosis?
A. Bowling
D. Don't know
B. Doing laundry

C. Aerobic dancing 


\section{Appendix G}

\section{Osteoporosis Health Belief Scale (OHBS) Exercise Subscales}

Below are some questions about your beliefs about osteoporosis. There is no right or wrong answer. We all have different experiences which will influence how we feel. After reading each statement, circle if you STRONGLY DISAGREE, DISAGREE, are NEUTRAL, AGREE, or STRONGLY AGREE with the statement.

It is important that you answer according to your actual beliefs and not according to how you feel you should believe or how you think we want you to believe. We need the answers that best explain how you feel.

Read each statement. Circle one best option that explains what you believe.

\section{Osteoporosis Health Belief Scale (OHBS) - Benefits of Exercise Subscale}

A1. Regular exercise prevents problems that would happen from osteoporosis

$\begin{array}{ccccc}1 & 2 & 3 & 4 & 5 \\ \text { Strongly } & \text { Disagree } & \text { Neutral } & \text { Agree } & \text { Strongly } \\ \text { Disagree } & & & & \text { Agree }\end{array}$

A2. You feel better when you exercise to prevent osteoporosis

$\begin{array}{ccccc}1 & 2 & 3 & 4 & 5 \\ \text { Strongly } & \text { Disagree } & \text { Neutral } & \text { Agree } & \text { Strongly } \\ \text { Disagree } & & & & \text { Agree }\end{array}$

A3. Regular exercise helps build strong bones

$\begin{array}{ccccc}1 & 2 & 3 & 4 & 5 \\ \text { Strongly } & \text { Disagree } & \text { Neutral } & \text { Agree } & \text { Strongly } \\ \text { Disagree } & & & & \text { Agree }\end{array}$

A4. Exercising to prevent osteoporosis improves the way your body looks

$\begin{array}{ccccc}1 & 2 & 3 & 4 & 5 \\ \text { Strongly } & \text { Disagree } & \text { Neutral } & \text { Agree } & \text { Strongly } \\ \text { Disagree } & & & & \text { Agree }\end{array}$

A5. Regular exercise cuts down on chances of broken bones

$\begin{array}{ccccc}1 & 2 & 3 & 4 & 5 \\ \text { Strongly } & \text { Disagree } & \text { Neutral } & \text { Agree } & \text { Strongly } \\ \text { Disagree } & & & & \text { Agree }\end{array}$

A6. You feel good about yourself when you exercise to prevent osteoporosis

$\begin{array}{ccccc}1 & 2 & 3 & 4 & 5 \\ \text { Strongly } & \text { Disagree } & \text { Neutral } & \text { Agree } & \text { Strongly } \\ \text { Disagree } & & & & \text { Agree }\end{array}$




\section{Osteoporosis Health Belief Scale (OHBS)- Barriers to Exercise Subscale}

B1. You feel like you are not strong enough to exercise regularly

$\begin{array}{ccccc}1 & 2 & 3 & 4 & 5 \\ \text { Strongly } & \text { Disagree } & \text { Neutral } & \text { Agree } & \text { Strongly } \\ \text { Disagree } & & & & \text { Agree }\end{array}$

B2. You have no place where you can exercise

$\begin{array}{ccccc}1 & 2 & 3 & 4 & 5 \\ \text { Strongly } & \text { Disagree } & \text { Neutral } & \text { Agree } & \text { Strongly } \\ \text { Disagree } & & & & \text { Agree }\end{array}$

B3. Your spouse or family discourages you from exercising

$\begin{array}{ccccc}1 & 2 & 3 & 4 & 5 \\ \text { Strongly } & \text { Disagree } & \text { Neutral } & \text { Agree } & \text { Strongly } \\ \text { Disagree } & & & & \text { Agree }\end{array}$

B4. Exercising regularly would mean starting new habits which is hard for you to do

$\begin{array}{lllll}1 & 2 & 3 & 4 & 5\end{array}$

Strongly Disagree $\quad$ Neutral Agree $\quad$ Strongly

Disagree Agree

B5. Exercising regularly makes you uncomfortable

$\begin{array}{llllll}1 & 2 & 3 & 4 & 5\end{array}$

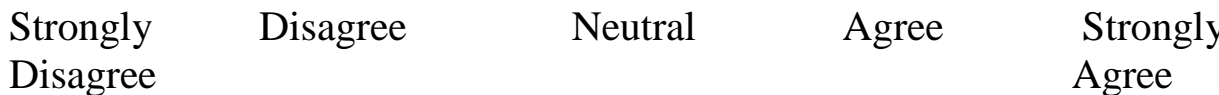

B6. Exercising regularly upsets your everyday routine

$\begin{array}{lllll}1 & 2 & 3 & 4 & 5\end{array}$

Strongly Disagree Neutral Agree

Disagree

Strongly

Agree 


\section{Appendix H}

\section{Osteoporosis Self-Efficacy Scale (OSES) Exercise Subscale}

We are interested in learning how confident you feel about doing the following activities. We all have different experiences, which will make us more or less confident in doing the following things. Thus, there is no right or wrong answers to this questionnaire.

EXERCISE means activities such as walking, golfing, biking, aerobic dancing. After reading each statement, circle if you STRONGLY DISAGREE, DISAGREE, NEUTRAL, AGREE or STRONGLY AGREE with the statement. It is important that you answer according to your actual confidence and not according to how confident you think you should be. We need the answers that best explain your confidence.

\section{Osteoporosis Self-Efficacy Scale Exercise Subscale}

If it were recommended that you do any of the following THIS WEEK, how confident or certain that I could: (circle the answer you choose)

1. Begin a new or different exercise program

$\begin{array}{ccccc}1 & 2 & 3 & 4 & 5 \\ \text { Strongly } & \text { Disagree } & \text { Neutral } & \text { Agree } & \text { Strongly } \\ \text { Disagree } & & & & \text { Agree }\end{array}$

2. Change exercise habits

$\begin{array}{ccccc}1 & 2 & 3 & 4 & 5 \\ \text { Strongly } & \text { Disagree } & \text { Neutral } & \text { Agree } & \text { Strongly } \\ \text { Disagree } & & & & \text { Agree }\end{array}$

3. Put forth the effort required to exercise

$\begin{array}{ccccc}1 & 2 & 3 & 4 & 5 \\ \text { Strongly } & \text { Disagree } & \text { Neutral } & \text { Agree } & \text { Strongly } \\ \text { Disagree } & & & & \text { Agree }\end{array}$

4. Do exercises even if they are difficult

$\begin{array}{ccccc}1 & 2 & 3 & 4 & 5 \\ \text { Strongly } & \text { Disagree } & \text { Neutral } & \text { Agree } & \text { Strongly } \\ \text { Disagree } & & & & \text { Agree }\end{array}$

5. Exercise for appropriate length of time

\begin{tabular}{|c|c|c|c|c|}
\hline $\begin{array}{c}1 \\
\text { Strongly } \\
\text { Disagree }\end{array}$ & $\begin{array}{c}2 \\
\text { Disagree }\end{array}$ & $\begin{array}{c}3 \\
\text { Neutral }\end{array}$ & $\begin{array}{c}4 \\
\text { Agree }\end{array}$ & $\begin{array}{l}\quad 5 \\
\text { Strongly } \\
\text { Agree }\end{array}$ \\
\hline the type o & cise that I & osed to & & \\
\hline 1 & 2 & 3 & 4 & 5 \\
\hline $\begin{array}{l}\text { Strongly } \\
\text { Disagree }\end{array}$ & Disagree & Neutral & Agree & $\begin{array}{l}\text { Strongly } \\
\text { Agree }\end{array}$ \\
\hline
\end{tabular}




\section{Appendix I}

\section{$\Longrightarrow$ S E N T A R A}

Ms. Hilda Taylor, MSN, RN, CNS

190 Red Fox Court

McGaheysville VA 22840

Ms. Taylor,

\section{RE: Exercise for Osteoporosis Prevention: A Health Belief Model Guided Intervention}

At the convened meeting of the Sentara RMH Medical Center (SRMH) Institutional Review Board on May 12,2015 the above referenced protocol, informed consent, pamphlet, pre-intervention questionnaire, fracture risk assessment tool (FRAX 8 ), telephone participant and principal investigator script and demographic survey were unanimously approved by the full board ( 9 votes for, 0 against, 0 abstentions).

The study will expire on May 12, 2016. At that time, the annual protocol will be reviewed for continuing approval. Any serious adverse events will require reporting per the Sentara RMH IRB guidelines.

Sincerely,

$$
\text { Atewart Pollock, MD/ipp }
$$

Chairman

Sentara RMH Medical Center

Institutional Review Board 
S E N T A R A

RMH Medical Center

\section{Institutional Review Board}

\section{CERTIFICATION OF APPROVAL}

Protocol Title:

Sponsor:

Principal Investigator:

$\underline{\text { Study Coordinator: }}$

\section{Exercise for Osteoporosis Prevention: A Health Belief} Model Guided Intervention

None

Hilda Taylor, RN, MSN, CNS

None

Board Approval Date: $\quad 5 / 12 / 15$

IRB Review Status: Full board

Approval Includes: $\quad$ Protocol, informed consent, pamphlet, pre-intervention questionnaire, fracture risk assessment tool (FRAX(B)), telephone participant and principal investigator script and demographic survey

Voting Record: Members Present: 9

Voted for: 9

Abstained: 0

\section{Status of Protocol: $\quad$ Active}

Expiration Date: $\quad 5 / 12 / 16$

This is to certify that the information contained herein is true and correct as reflected in the records of the Sentara RMH Medical Center Institutional Review Board. Members of the IRB will abstain from voting when presenting a protocol for approval.

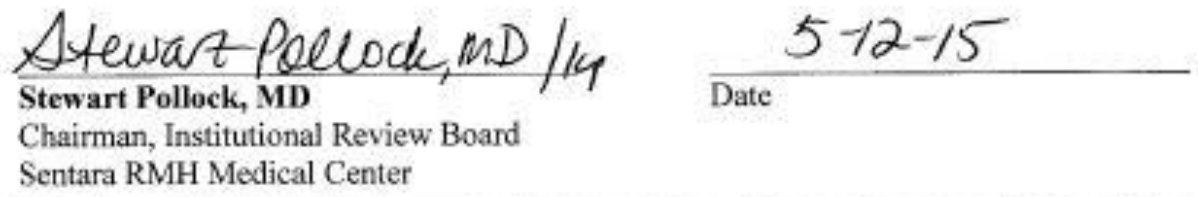

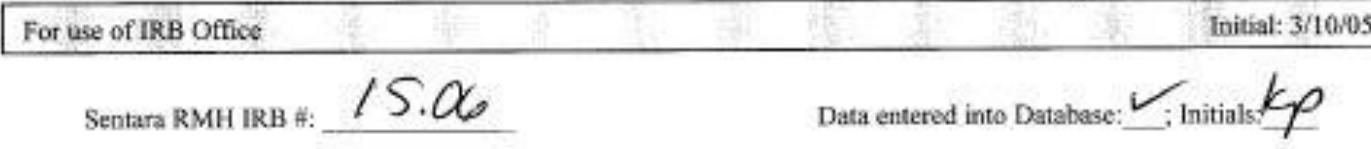


Appendix $\mathbf{J}$

UMUERSITY

VIRGINIA

IRB-HSR

\section{Institutional Review Board for Health Sciences Research}

DETERMINATLON OF UVA AGENT FORM

INFORMATION ABOUT THIS FORM

- This form is to determine if UVa personnel are or are not considered to be working as an Agent* for UVa on this project.

- If it is determined that UVa personnel are considered to be working as an Agent* for UVa the study team will be required to submit an additional submission to the IRB-HSR, unless the project is determined to not involve human subject research. See Determination of Human Subject Research Form

*Agent-all individuals (including students) performing instifutionally designated activities or extercising instufutionally delegated authority or responsubiluty.

Enter responses electronically. Email the completed form to IRBMSR@yirginia.edu for pre-review. An IRB staff member will reply with any changes to be made.

\begin{tabular}{|c|c|}
\hline Name of Individual to be Working on Project: & Hilda Amalia Taylor \\
\hline Email: & bat5hs@uva.cdu \\
\hline Phone: & 5403833200 \\
\hline \multicolumn{2}{|l|}{ UVa Messenger Mail Box \# } \\
\hline Project/Protocol Title if Known: & $\begin{array}{l}\square \text { Unknown or } \\
\text { Title: Exercise for Osteoporosis Prevention: } \\
\text { A Health Belief Model Guided Intervention }\end{array}$ \\
\hline $\begin{array}{l}\text { Explain your role in the project: } \\
\text { ( } 200 \text { words or less) }\end{array}$ & $\begin{array}{l}\text { UVA DNP capstone study. Copy of Senture IRB } \\
\text { approyal attechec to email } \\
\text { Purpose: The proposed study goal is to improve self- } \\
\text { efficacy for osteoporosis exercise prevention behaviors in } \\
\text { a high risk screened population served by Sentara RMH } \\
\text { Medical Center. The underlying assumption of the } \\
\text { proposed study is that sufficient osteoporosis knowledge } \\
\text { mediated by attitudes, beliefs and self-efficacy for bone } \\
\text { health exercise preventive behaviors are driving factors } \\
\text { in the managemeat of osteoporosis. } \\
\qquad \text { Aim 1: To assess higher risk screened } \\
\text { postmenopausal women's baseline knowledge, } \\
\text { beliefs and self-efficacy scores for osteoporosis } \\
\text { Aim 2: To assess and compare pre- and post-intervention } \\
\text { osteoporosis self-efficacy exercise scores. } \\
\text { Aim 3: To explore the effectiveness and feasibility of an } \\
\text { osteoporosis exercise prevention health fair targeted for } \\
\text { improving self-efficacy and engagement in preventive } \\
\text { exercise. } \\
\text { Research question: Will participants in an osteoporosis } \\
\text { exercise prevention targeted health fair significantly } \\
\text { improve their osteoporosis self-efficacy exercise scores? } \\
\text { Intervention: Tbe exercise promotion health fair is }\end{array}$ \\
\hline Phone: 434-924-20 & $\begin{array}{l}\text { Finia_edufyorlib/her/index.html } \\
\text { Fax: 434-924-2932 Box } 800483\end{array}$ \\
\hline
\end{tabular}

Version date: 03/19/15

Page 1 of 3 